\title{
Biodiesel synthesis from Ceiba pentandra oil by microwave irradiation- assisted transesterification: ELM modeling and optimization
}

\author{
A.S. Silitonga ${ }^{\text {a, }}{ }^{*}$, A.H. Shamsuddin ${ }^{\text {b }}$, T.M.I. Mahlia ${ }^{c}$, Jassinne Milano ${ }^{\text {d, }}{ }^{* *}$, F. Kusumo ${ }^{\text {e }}$, \\ Joko Siswantoro $^{\text {f }}$, S. Dharma ${ }^{a}$, A.H. Sebayang ${ }^{a}$, H.H. Masjuki ${ }^{d}$, Hwai Chyuan Ong ${ }^{d}$ \\ a Department of Mechanical Engineering, Politeknik Negeri Medan, 20155, Medan, Indonesia \\ ${ }^{\mathrm{b}}$ Institute of Sustainable Energy, Universiti Tenaga Nasional, 43000, Kajang, Selangor, Malaysia \\ c School of Systems, Management and Leadership, Faculty of Engineering and Information Technology, University of Technology Sydney, NSW, 2007, \\ Australia \\ d Department of Mechanical Engineering, Faculty of Engineering, University of Malaya, 50603, Kuala Lumpur, Malaysia \\ e Department of Computer Science \& Information Technology, College of Computer Science \& Information Technology Universiti Tenaga Nasional, 43000, \\ Kajang, Selangor, Malaysia \\ ${ }^{\mathrm{f}}$ Department of Informatics Engineering, Faculty of Engineering, Universitas Surabaya, Jl. Kali Rungkut, Surabaya, 60293, Indonesia
}

\section{A R T I C L E I N F O}

\section{Article history:}

Received 14 July 2018

Received in revised form

20 June 2019

Accepted 11 July 2019

Available online 12 July 2019

\section{Keywords:}

Ceiba pentandra biodiesel

Extreme learning machine

Cuckoo search algorithm

Microwave irradiation-assisted

transesterification

Alternative fuel

\begin{abstract}
A B S T R A C T
In this study, microwave irradiation-assisted transesterification was used to produce Ceiba pentandra biodiesel, which accelerates the rate of reaction and temperature within a shorter period. The improvement of biodiesel production requires a reliable model that accurately reflects the effects of input variables on output variables. In this study, an extreme learning machine integrated with cuckoo search algorithm was developed to predict and optimize the process parameters. This model will be useful for virtual experimentations in order to enhance biodiesel research and development. The optimum parameters of the microwave irradiation-assisted transesterification process conditions were obtained as follows: (1) methanol/oil ratio: $60 \%$, (2) potassium hydroxide catalyst concentration: $0.84 \%(\mathrm{w} / \mathrm{w}),(3)$ stirring speed: $800 \mathrm{rpm}$, and (4) reaction time: $388 \mathrm{~s}$. The corresponding Ceiba pentandra biodiesel yield was $96.19 \%$. Three independent experiments were conducted using the optimum process parameters and the average biodiesel yield was found to be $95.42 \%$. In conclusion, microwave irradiation-assisted transesterification is an effective method for biodiesel production because it is more energy-efficient, which will reduce the overall cost of biodiesel production.
\end{abstract}

() 2019 Elsevier Ltd. All rights reserved.

\section{Introduction}

Biodiesels are promising alternative fuels for petroleum-derived diesel fuels owing to their similarities between the physicochemical properties of biodiesels and those of diesel [1]. Biodiesels are non-toxic and environmentally friendly with lower carbon dioxide $\left(\mathrm{CO}_{2}\right)$, carbon monoxide $(\mathrm{CO})$, and nitrogen oxide $\left(\mathrm{NO}_{\mathrm{x}}\right)$ emissions compared with petroleum-derived diesel. The higher flash points of biodiesels facilitate in their storage and transportation [2].

There is growing interest in biodiesel production worldwide

\footnotetext{
* Corresponding author. Department of Mechanical Engineering, Politeknik Negri Medan, 20155, Medan, North Sumatra, Indonesia.;

** Corresponding author.;

E-mail addresses: arridina@polmed.ac.id, ardinsu@yahoo.co.id (A.S. Silitonga), jassinneemilano@hotmail.com, jassinneemilano.jm@gmail.com (J. Milano).
}

because of its eco-friendliness and additionally, biodiesels can be produced from renewable sources. Biodiesels have higher flash points, rendering these fuels safer alternatives for handling and transportation compared with diesel [3]. Biodiesels also have more favorable combustion, engine performance, and exhaust emission characteristics compared with diesel including lower $\mathrm{CO}$, particulate matter (PM), and unburned hydrocarbons (UHC) [4]. The escalating increase in energy demands due to industrialization has led to a significant increase in the imports of crude oils in developing countries.

Computational tools are commonly used to analyze and/or design complex systems [5]. Modeling has gained popularity because of its flexibility and its ability to simulate and analyze realworld systems in detail. Hence, modeling can be used as a supporting tool to complement experimental techniques. Simulation models require fewer restrictive assumptions to represent complex 
dynamic systems and fairly complex models can be developed with relatively high dimensionality [6]. Hence, modeling is essentially a trial-and-error process, in which a set of inputs is used to predict a set of outputs. A good system design is attained once the desired performance is achieved. The simulation process is repeated until a satisfactory set of performance measures is obtained.

Many studies have examined the use of traditional artificial neural networks (ANNs), which are well-known types of evolutionary computational methods and which have gained popularity over the last few decades. Several ANN topologies have been used to optimize biodiesel production processes (esterification and transesterification reactions) as well as to improve the physicochemical properties, engine performance, and exhaust emission characteristics of biodiesels [7,8]. The efficiency of ANNs in modeling bioprocesses has been reported in several studies [9-11]. However, there are many drawbacks with conventional ANNs owing to their limitations in learning process, such as the existence of multiple local minima, slow learning speed, large training data size, and poor generalization performance. In addition, the users need to determine the optimal ANN architecture.

Extreme learning machine (ELM) is a mathematical modeling approach that can be used to solve the aforementioned problems $[10,12]$. The ELM is a single-hidden-layer feedforward ANN where the parameters of the hidden layer are initialized randomly. Moreover, ELM can calculate the output weights analytically using the Moore-Penrose generalized inverse. For this reason, ELM is advantageous because of its speed and better generalization capability compared with conventional ANNs [12,13]. Sebayang et al. [14] used ELM to predict the engine performance and exhaust emission characteristics of Manihot glaziovii bioethanol-gasoline blends. The results showed the coefficient of determination $\left(R^{2}\right)$ is close to 1 and the mean absolute percentage error (MAPE) is less than $3 \%$ for all parameters. The results indicate the ELM model is capable of predicting the engine performance and exhaust emissions of bioethanol-gasoline fuel blends.

Wong et al. [15] compared three mathematical models (ELM, least-squares support vector machine, and radial basis function neural network) to determine the optimal biodiesel ratio that can reduce exhaust emissions within the engine operation range. The results showed the mean absolute percentage errors for the test data sets $\left(M A P E_{\text {test }}\right)$ were 2.06 and $34.74 \%$ whereas the root mean square percentage errors for the test data sets $\left(R M S P E_{\text {test }}\right)$ were 0.29 and $28.01 \%$. This indicates that ELM, as one of the potential modeling techniques, is the best modeling technique for optimization purposes because of its high accuracy and accelerated modeling time. Therefore, ELM modeling has been used to predict the engine performance and exhaust emission characteristics of biodiesels. Kusumo et al. [7] compared kernel-based extreme learning machine (K-ELM) and ANN models for Ceiba pentandra biodiesel production. The results showed the K-ELM provided more reliable predictions compared with the ANN model.

\subsection{Microwave irradiation-assisted transesterification}

Biodiesel can be produced by conventional heating, enzymatic catalysis, supercritical methanol, and microwave irradiationassisted transesterification [16-18]. Microwave irradiationassisted transesterification is more energy-efficient owing to the direct transfer of energy to the reactants through microwave radiation, which eliminates the need for preheating. In recent years, microwave reactors have been used to convert triglycerides in oils into biodiesels because of their high product selectivity, significant energy savings, and accelerated transesterification reaction compared with conventional heating systems [19-21]. Transesterification reaction involves transforming triglycerides in oils or fats into fatty acid alkyl esters in the presence of an alcohol (e.g., methanol or ethanol) and catalyst, producing glycerol as a byproduct $[22,23]$. The cost of biodiesel production is related to the cost of raw materials (production and processing), catalysts, biodiesel processing (energy, consumables and labor), transportation (raw materials and final products), as well as local and national taxes [24]. To date, crude oils are primarily used as feedstocks in most biodiesel plants, where the cost of vegetable oils accounts for nearly $80 \%$ of the overall biodiesel production cost $[1,17,18]$. Microwave reactors have been used in transesterification reactions, and microwave irradiation-assisted transesterification has been accepted as a suitable method to separate and purify thermosensitive compounds with high molecular weights [19,25,26]. This is possible owing to the small distance between the condenser and chamber, which is in the order of the mean free path of the evaporating molecules. Microwave reactors are better than conventional reactors as they can be used to increase biodiesel production and attain higher production capacities [18,27,28]. A simple and robust design of tubular reactors with static mixers in the microwave reactors can overcome the shortcomings of conventional heating reactors by efficiently increasing the mass transfer rate between the phases without the need for moving parts, which reduces investment, operation, and maintenance costs $[29,30]$. The objective of this study was to optimize the parameters of microwave irradiation-assisted transesterification to produce Ceiba pentandra biodiesel by using ELM coupled with cuckoo search (CS) algorithm.

\section{Materials and methods}

\subsection{Materials and reagents}

Crude Ceiba pentandra oil was sourced from Kebumen, Central Java, Indonesia, which has about 23 million tons of Ceiba Pentandra stalks with an average production of 3 tons per hectare. The average oil seed yield is $1280 \mathrm{~kg} / \mathrm{ha}$. Ceiba Pentandra seeds have about $25-28 \%(w / w)$ of oil in each fruit [31]. In this study, crude Ceiba pentandra oil (CCPO) was extracted using a screw extruder machine. However, to increase the yield of CCPO, the seeds were repeatedly pressed using a manual hydraulic pressing machine.

Oxidation stability is one of the parameters used to assess the quality of a fuel. Oxidation stability indicates the degree of oxidation and the potential reactivity of a fuel with air. This parameter can be used to determine if antioxidants are needed. Oxidation occurs due to the presence of unsaturated fatty acid chains and double bonds in the parent molecules, which immediately react with the oxygen as soon as the fuel is exposed to air [32]. The chemical composition of crude oils render these oils more susceptible to oxidative degradation compared with diesel [33]. The Rancimat method is used to measure the oxidative stability of fuels

Table 1

Fatty acid composition of the CCPO.

\begin{tabular}{|c|c|}
\hline Fatty acid & Composition $(\%(w / w))$ \\
\hline C12:0 (Lauric acid) & 0.1 \\
\hline C14:0 (Myristic acid) & 0.1 \\
\hline C16:0 (Palmitic acid) & 20.8 \\
\hline C16:1 (Palmitoleic acid) & 0.5 \\
\hline C18:0 (Stearic acid) & 4.2 \\
\hline C18:1 (Oleic acid) & 17.0 \\
\hline C18:2 (Linoleic acid) & 38.2 \\
\hline C18:3 (Linolenic acid) & 1.3 \\
\hline C20:0 (Arachidic acid) & 0.8 \\
\hline 18: ${ }^{\mathrm{a}} \mathrm{CE}$ (Malvalic acid) & 16.8 \\
\hline
\end{tabular}

a $\mathrm{CE}$ : Cyclopropane ester. 
in the ASTM D6751 and EN 14214 standard methods. Based on the fatty acid composition of the CCPO shown in Table 1, it can be expected the Ceiba pentandra biodiesel will have good oxidation stability. Proper handling and preventing the crude oil from exposure to air and sunlight during the storage period will help prolong the oxidation stability of the oil. The CСPO needs to be transesterified into biodiesel for it to be used in compression ignition engines.

The following reagents were used for biodiesel production: (1) methanol (purity: 99.9\%, American Chemical Society-grade reagent), sulfuric acid (purity: $>98.9 \%$ ), ortho-phosphoric acid (purity: $85 \%$ ), anhydrous sodium sulfate (purity: 99\%), sodium hydrogen carbonate, and potassium hydroxide pellets (purity: $99 \%)$.

\subsection{Instruments and apparatus}

The physicochemical properties of the biodiesel (kinematic viscosity, density, flash point, cloud point, pour point, higher heating value, acid value, oxidation stability, and copper strip corrosion) were measured according to the ASTM D445, ASTM D127, ASTM D93, ASTM D2500, ASTM D240, ASTM D664, EN 14112, and ASTM D130 standard test methods respectively. Agilent 7890A gas chromatograph system equipped with a flame ionization detector (FID) was used to determine the fatty acid methyl ester (FAME) content of the biodiesels. HP Innowax column (length $\times$ inner diameter $\times$ film thickness: $30 \mathrm{~m} \times 0.25 \mathrm{~mm} \times$ $0.25 \mu \mathrm{m}$ ) was used for FAME measurements. A gas chromatograph system equipped with an FID and cool on-column injector was used to measure the glycerol and glyceride content of the biodiesels according to the EN 14105:2011 standard. Agilent VF-5ht Ultimetal (length $\times$ inner diameter $\times$ film thickness: $15 \mathrm{~m} \times 0.32 \mathrm{~mm} \times$ $0.1 \mu \mathrm{m}$ ) was used for glycerol and glyceride testing. The resulting mixture was immediately analyzed using Fourier transform infrared (FTIR) spectrometer (Model: TENSOR 27, Bruker, USA). Each experiment was conducted in triplicate and the data was expressed in terms of mean and standard deviation.

\subsection{Microwave reactor}

Anton Paar Monowave 400 microwave reactor with Autosampler MAS 24 was used in this study. This reactor was equipped with infrared sensors for precise temperature control and pressure sensors in order to monitor the reaction in the closed vessel. The built-in magnetic stirrer provides adequate stirring in order to attain a homogeneous mixture, as shown in Figs. 1 and 2. The Monowave 400 microwave reactor chamber has three stages: (1) the closed vessel was heated to the desired temperature, (2) the temperature was maintained at the set temperature over a specific time, and (3) the closed vessel was cooled to the desired temperature in order to terminate the transesterification reaction. During the reaction, the power output was controlled based on the set temperature for the experiment. The power output is automatically controlled to prevent the reaction from becoming exothermic during the transesterification reaction. The technical specifications of the Anton Paar Monowave 400 microwave reactor with Autosampler MAS 24 are shown in Table 2. The microwave irradiation produced goes through the glass reaction vessel wall and directly heats up the reaction mixture. The conversion of electromagnetic energy into heat energy is highly efficient, resulting in extremely fast heating rates within minutes. The microwave irradiation provides energy to the molecules such that the molecules stretch and rotate, resulting in energy activation. The rapid heating to the set temperature and immediate cooling after the conversion process suppresses the formation of by-products.

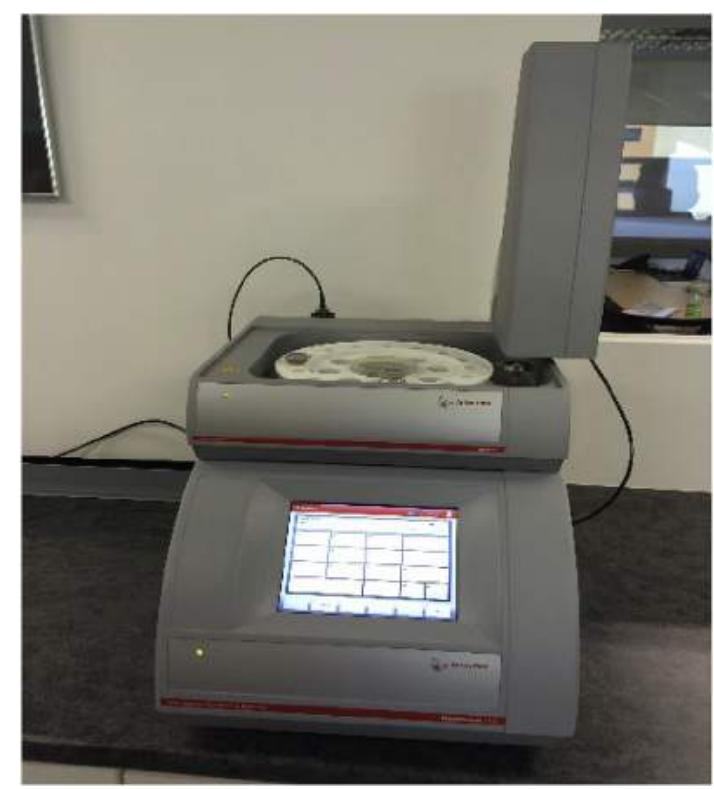

Fig. 1. Anton Paar Monowave 400 microwave reactor.

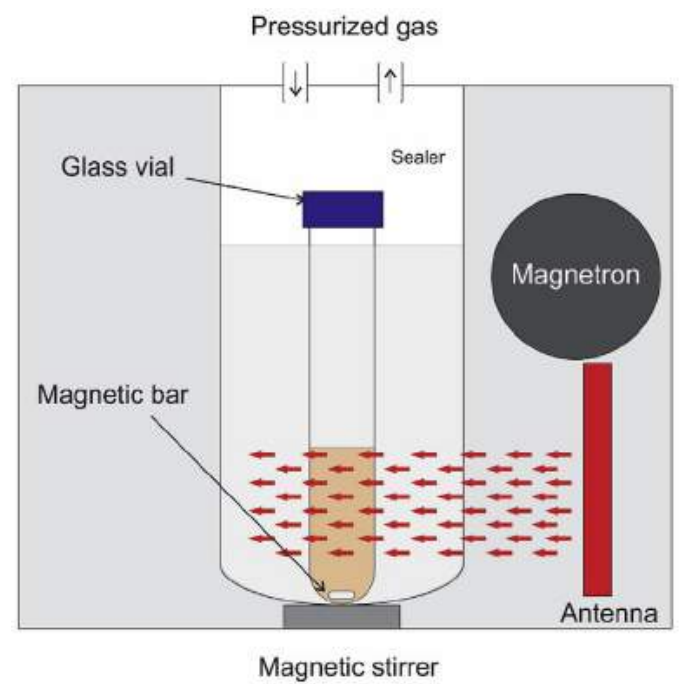

Fig. 2. Schematic of the experimental setup using the Anton Paar Monowave 400 microwave reactor.

Table 2

Technical specifications of the Anton Paar Monowave 400 microwave reactor.

\begin{tabular}{ll}
\hline Parameters & Monowave 400 \\
\hline Maximum filling volume & $20 \mathrm{~mL}$ for a $30-\mathrm{mL}$ vial \\
Maximum operation pressure & $30 \mathrm{bars}(435 \mathrm{psi})$ \\
Maximum infrared temperature & $300^{\circ} \mathrm{C}$ \\
Maximum fiber-optic temperature & $300^{\circ} \mathrm{C}$ \\
Maximum power & $850 \mathrm{~W}$ \\
Vial material & Borosilicate glass \\
Cap material & Polyether ether ketone (PEEK) \\
Camera & Integrated \\
Autosampler MAS24 & Yes \\
Seal material & Teflon-coated silicone \\
\hline
\end{tabular}

\subsection{Esterification process}

It was necessary to pretreat the CCPO in order to reduce its free 
fatty acid content and acid value prior to the transesterification process. Acid-catalyzed esterification was used for this purpose, where sulfuric acid $\left(\mathrm{H}_{2} \mathrm{SO}_{4}\right)$ was chosen as the catalyst. The following parameters were used for the acid-catalyzed esterification process: (1) methanol: $40 \%(\mathrm{v} / \mathrm{v}),(2) \mathrm{H}_{2} \mathrm{SO}_{4}$ concentration: $1.8 \%(\mathrm{v} / \mathrm{v})$, and (3) stirring speed: $800 \mathrm{rpm}$. These values were chosen based on the work of Kusumo et al. [7]. The esterification process was assisted by microwave irradiation using the microwave reactor. The reaction time for the esterification process was varied at $120,180,240,300$, and $360 \mathrm{~s}$ while the reaction temperature was fixed at $100^{\circ} \mathrm{C}$ [34]. After the esterification process, the reaction mixture was left to settle under gravity in a separating funnel for $2 \mathrm{~h}$. The by-products and catalyst were removed after the esterification process and the product was washed with warm deionized water ( $20 \%$ of the volume of the products) at $40{ }^{\circ} \mathrm{C}$ in order to remove impurities. The methanol and water residues were evaporated from the esterified oil using a rotary evaporator under vacuum.

\subsection{Transesterification process}

Anton Paar Monowave 400 high-performance microwave reactor with Autosampler MAS24 was used for the microwave irradiation-assisted transesterification, where the esterified oil was converted into Ceiba pentandra methyl ester (CPME). The steps involved in the production of CPME from the esterified Ceiba pentandra oil by microwave irradiation-assisted transesterification are summarized in the form of a flow chart (see Fig. 3).

Box-Behnken design was used for the experimental design. Four parameters were chosen for this study: (1) stirring speed $(600,750$, $900 \mathrm{rpm}),(2)$ reaction time $(240,360,480 \mathrm{~s}),(3)$ potassium hydroxide $(\mathrm{KOH})$ catalyst concentration $(0.6,0.8,1.0 \%(\mathrm{w} / \mathrm{w}))$, and $(4)$ methanol/oil ratio $(50,60,70 \%)$. The total number of experimental runs was 29. The Box-Behnken experimental design for the microwave irradiation-assisted transesterification process is shown in Table 3. The operating conditions followed Milano et al. [34], Jermolovicius et al. [35], and El Sherbiny et al. [36], who conducted optimization studies of biodiesel production from edible and nonedible oils using microwave irradiation-assisted method. Milano et al. [34] recommended: (1) methanol/oil ratio: 59.60\%, (2) catalyst concentration: $0.77 \%$, (3) stirring speed: $600 \mathrm{rpm}$, and (4) reaction time: $429 \mathrm{~s}$, while Jermolovicius et al. [35] suggested reaction time can be completed at $450 \mathrm{~s}$ with $1.76 \mathrm{~W} / \mathrm{g}$ of microwave power and lastly Sherbiny et al. [36] recommended (1) methanol/oil molar ratio: 7.5:1 (approximately methanol/oil ratio:35\%), (2) reaction time: $120 \mathrm{~s}$, (3) catalyst concentration: $1.5 \%$. The methyl ester yield obtained from the transesterification process was based on the following equation:

Methyl ester yield $(\%)=\frac{M_{M E}}{M_{O}} \times 100$

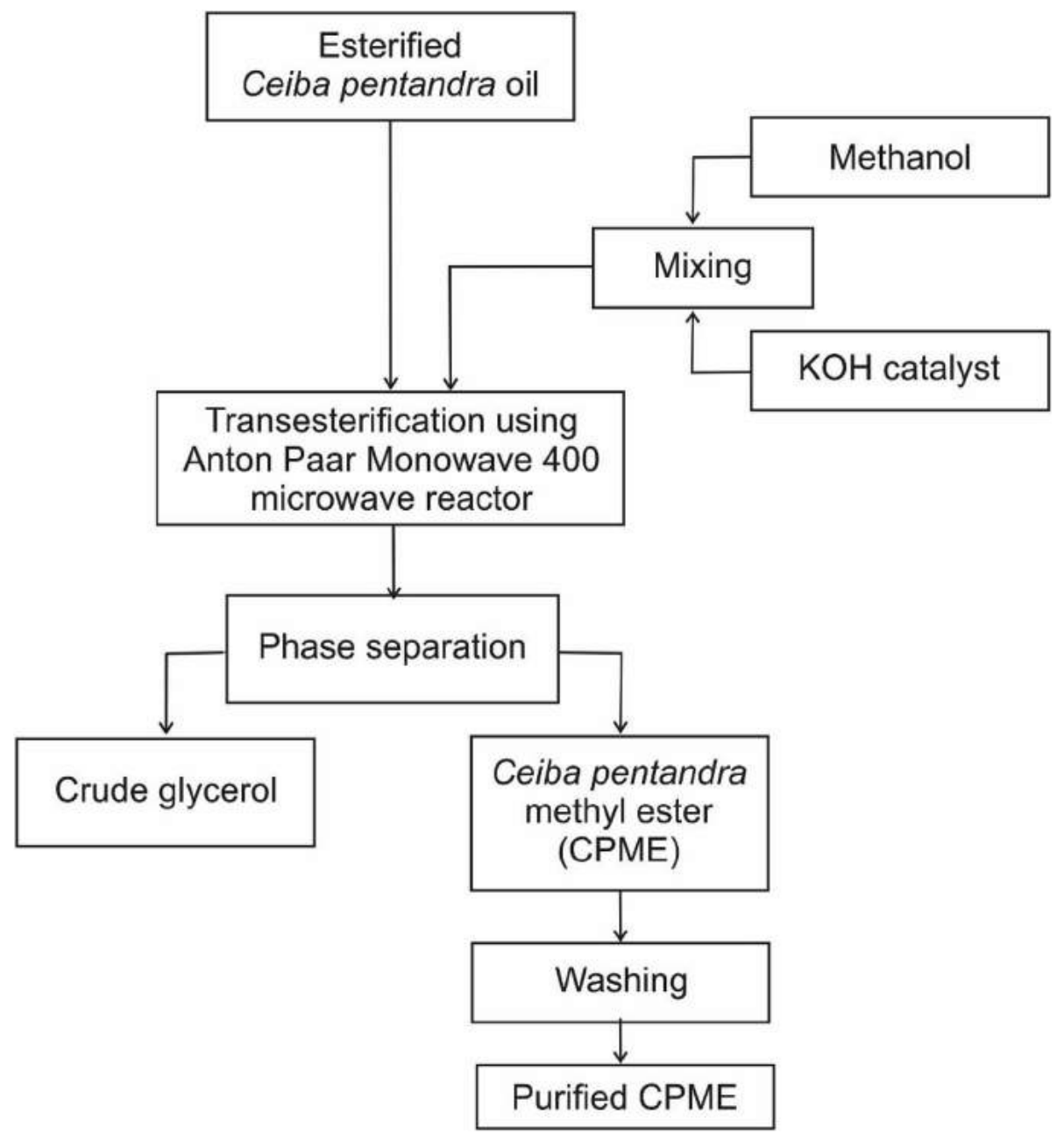

Fig. 3. Steps involved in microwave irradiation-assisted transesterification process of esterified Ceiba Pentandra oil. 
Table 3

Box-Behnken experimental design for the microwave irradiation-assisted transesterification process.

\begin{tabular}{|c|c|c|c|c|c|c|}
\hline Run & $\begin{array}{l}\text { Stirring speed } \\
(\mathrm{rpm})\end{array}$ & $\begin{array}{l}\text { Reaction } \\
\text { time }(s)\end{array}$ & $\begin{array}{l}\text { KOH catalyst } \\
\text { concentration }(\%(w / w))\end{array}$ & $\begin{array}{l}\text { Methanol/oil } \\
\text { ratio (\%) }\end{array}$ & $\begin{array}{l}\text { Ceiba pentandra methyl ester yield from Box- } \\
\text { Behnken experiment (\%) }\end{array}$ & $\begin{array}{l}\text { Ceiba pentandra methyl ester yield from } \\
\text { ELM prediction (\%) }\end{array}$ \\
\hline 1 & 750 & 240 & 0.8 & 50 & 75.99 & 76.00 \\
\hline 2 & 750 & 360 & 0.8 & 60 & 93.25 & 94.62 \\
\hline 3 & 900 & 360 & 1.0 & 60 & 89.77 & 89.77 \\
\hline 4 & 750 & 240 & 0.6 & 60 & 71.25 & 71.28 \\
\hline 5 & 750 & 240 & 0.8 & 70 & 79.17 & 80.58 \\
\hline 6 & 600 & 360 & 0.8 & 50 & 79.14 & 81.21 \\
\hline 7 & 750 & 360 & 1.0 & 70 & 84.91 & 84.92 \\
\hline 8 & 900 & 480 & 0.8 & 60 & 90.22 & 90.21 \\
\hline 9 & 750 & 480 & 0.6 & 60 & 75.18 & 75.24 \\
\hline 10 & 750 & 360 & 1.0 & 50 & 89.00 & 87.46 \\
\hline 11 & 750 & 360 & 0.8 & 60 & 94.42 & 94.62 \\
\hline 12 & 600 & 360 & 0.6 & 60 & 75.64 & 75.64 \\
\hline 13 & 600 & 480 & 0.8 & 60 & 83.21 & 83.21 \\
\hline 14 & 900 & 360 & 0.8 & 70 & 91.33 & 91.32 \\
\hline 15 & 600 & 360 & 1.0 & 60 & 85.05 & 85.04 \\
\hline 16 & 600 & 240 & 0.8 & 60 & 75.53 & 75.53 \\
\hline 17 & 750 & 360 & 0.8 & 60 & 94.99 & 94.62 \\
\hline 18 & 600 & 360 & 0.8 & 70 & 86.11 & 86.10 \\
\hline 19 & 750 & 240 & 1.0 & 60 & 77.27 & 77.32 \\
\hline 20 & 900 & 360 & 0.8 & 50 & 89.27 & 89.26 \\
\hline 21 & 750 & 360 & 0.8 & 60 & 94.19 & 94.62 \\
\hline 22 & 750 & 480 & 0.8 & 50 & 86.46 & 86.46 \\
\hline 23 & 750 & 360 & 0.8 & 60 & 94.39 & 94.62 \\
\hline 24 & 900 & 360 & 0.6 & 60 & 81.97 & 81.92 \\
\hline 25 & 750 & 360 & 0.6 & 50 & 74.63 & 74.63 \\
\hline 26 & 750 & 360 & 0.6 & 70 & 83.41 & 83.41 \\
\hline 27 & 750 & 480 & 0.8 & 70 & 89.16 & 89.16 \\
\hline 28 & 750 & 480 & 1.0 & 60 & 87.02 & 87.06 \\
\hline 29 & 900 & 240 & 0.8 & 60 & 81.79 & 81.79 \\
\hline \multicolumn{5}{|c|}{$R^{2}$} & 0.992 & \\
\hline \multicolumn{5}{|c|}{ RMSE } & 0.142 & \\
\hline
\end{tabular}

where $M_{M E}$ is the weight of the methyl ester produced in grams ( $\mathrm{g}$ ), and $M_{O}$ is the weight of the esterified Ceiba pentandra oil in grams (g).

The number of experimental runs $(N)$ required for the BoxBehnken experimental design was based on the following equation:

$N=2 k(k-1)+N_{c}$

where $k$ is the number of factors and $N_{c}$ is the number of central points [37].

\subsection{ELM model}

The efficacy of ELM model is dependent on input data and therefore, it is crucial to scale the input and output data. In this study, the experimental input and output data were normalized using a simple normalization method [15]. The training model dataset was normalized using the following equation [7]:

$N_{i}=\frac{x_{i}-m}{s}$

where $N_{i}$ represents the normalized parameter, $x_{i}$ is the original variable, and $m$ and $s$ represent the mean and standard deviation of $x_{i}$ respectively

Since all of the values in the training process were normalized, the values predicted by the models needed to be denormalized using the inverse of Eq. (1). The data was normalized within a range of $0.1-0.9$ [14]. After normalization, the data were randomized before training.

The ELM was initially developed for single-hidden-layer feedforward networks (SLFNs). The SLFNs are widely used to approximate complex nonlinear mappings directly from the input samples where the parameters of the hidden layer in ELM are initialized randomly. Output weights were calculated using Moore-Penrose generalized inverse. The output function of the ELM for generalized SLFNs is expressed as [15,38]:

$f_{L}(x)=\sum_{i=1}^{L} \beta_{i} G\left(w_{i}, b_{i}, x\right), x \in R^{n}, a_{i} \in R^{n}$

where $w_{i}$ and $b_{i}$ are the learning parameters of the hidden nodes, $\beta_{i}$ is the weight that connects the $i$ th hidden node and the output node. The function $G\left(w a_{i}, b_{i}, x\right)$ shows the output value of the $i$ th hidden node for the input $x$. The additive hidden node with the activation function $g(x): R \rightarrow R$ (e.g., sigmoid and threshold) is expressed as:

$G\left(w_{i}, b_{i}, x\right)=g\left(\sum_{j=i}^{n} w_{i j} x_{j}+b_{i}\right), b_{i} \in R$

where $w_{i j}=\left[w_{i 1}, w_{i 2}, \ldots, w_{i n}\right]^{T}$ is the weight vector that connects the input layer and $i$ is the hidden node $i$ with input to $j, b_{i}$ is the bias of the $i$ th hidden node and $a_{i}, x=\left[x_{1}, x_{2}, \ldots, x_{n}\right]^{T}$ is the inner product of vector $a_{i}$ in $R^{n}$.

By using Eq. (3), one can determine $G\left(w_{i j}, b_{i}, X\right)$ for the radial basis function (RBF) hidden node with the activation function $g(x)$ : $R \rightarrow R$ (e.g., Gaussian) given in Eq. (4) as follows [39]:

$G\left(w_{i}, b_{i}, x\right)=g\left(b_{i} \sqrt{\sum_{j=i}^{n}\left(x_{j}-w_{i j}\right)^{2}}\right)^{T}, b \in R^{+}$

Here, $w_{i}$ and $b_{i}$ represent the center and impact factor of $i$ th RBF node, $R^{+}$represents the set of all positive real values. An RBF 
network forms if the SLFN has RBF nodes in its hidden layer. For $N$, the arbitrary distinct sample is $\left(x_{i}, t_{i}\right) \in R^{n} \times R^{m}$ where the $n \times 1$ input vector is represented by $x_{i}$ and the $m \times 1$ target vector is represented by $t_{i}$. If an SLFN with $L$ hidden nodes approximate $N$ samples with zero error, this implies that $\beta_{i}, w_{i}$ and $b_{i}$ exist such that:

$f_{i}(x)=\sum_{i=1}^{L} \beta_{i} G\left(w_{i}, b_{i}, x\right), j=1, \ldots, N$

Eq. (5) may be expressed compactly as [15]:

$H \beta=T$

where

$H(\tilde{w}, \tilde{b}, \tilde{x})=\left[\begin{array}{lll}G\left(w_{1}, b_{1}, x_{1}\right) & \ldots & G\left(w_{L}, b_{L}, x_{1}\right) \\ G\left(w_{1}, b_{1}, x_{N}\right) & \ldots & G\left(w_{L}, b_{L}, x_{N}\right)\end{array}\right]_{N x L}$

with $\bar{w}=w_{1}, \ldots, w_{L} ; \tilde{b}=b_{1}, \ldots, b_{L} ; \tilde{x}=x_{1}, \ldots, x_{L}$

$\beta=\left[\begin{array}{c}\beta_{1}^{T} \\ \vdots \\ \beta_{L}^{T}\end{array}\right]_{L x m} \quad$ and $T=\left[\begin{array}{c}t_{1}^{T} \\ \vdots \\ t_{L}^{T}\end{array}\right]_{N x m}$

It shall be noted that $H$ is the hidden layer output matrix of the SLFN, where the $i$ th column of $H$ is the output of the $i$ th hidden node with respect to the inputs $x_{1}, \ldots, x_{n}$ in Eq. (7) and (8). Unlike traditional learning algorithms, the ELM tends to cover not only the smallest training error but also the smallest norm of output weights compared with conventional learning algorithms which improves the performance of the regression model. The ELM is based on the idea the parameters of the hidden layer are independent of the training samples and the hidden layer of the generalized SLFNs does not need to be tuned [38].

\subsection{Cuckoo search algorithm}

The CS algorithm consists of three major rules:

1) Each cuckoo randomly finds a nest to lay eggs and lays one egg at a time.

2) The best nest with high-quality eggs will be carried over to the next generation.

3) The number of available host nests is fixed and the host can detect the egg laid by a cuckoo with probability $p_{a} \in[0,1]$. In this case, the host bird that detects the egg laid by the cuckoo can either throw the egg or build a new nest elsewhere. The last strategy is approximated by the fraction $p_{a}$ of the $n$ nests being replaced by new nests $[40,41]$.

Lévy flight based on the Lévy distribution with infinite mean and variance were used to generate new solutions, i.e., $X_{i}^{(t+1)}$. This behavior was used to generate new solutions for a cuckoo based on the following equation [42]:

$X_{i}^{(t+1)}=X_{i}^{(t)}+\alpha \operatorname{Levy}(\lambda)$

where ( $\propto>0$ ) is the step size, which is adjusted according to the scale of the problem of interest.

\subsection{Random sub-sampling cross validation}

Random sub-sampling cross validation was adopted in this study since the number of datasets (29) used to assess the performance of the ELM model may not be sufficiently large. Random sub-sampling is a multiple holdout based on the idea that the data is randomly split into subsets, where the size of each subset is determined by the user $[18,43]$. A total of 23 datasets and 6 datasets was used for training and testing respectively. The procedure was repeated ten times and the average absolute deviation $(A A D)$ was determined. The standard deviation $(S D)$ was determined based on Eq (13):

$A A D=\frac{1}{n}\left(\sum_{i=1}^{n}\left(\frac{\left|\left(y_{e i}-y_{p i}\right)\right|}{y_{e i}}\right)\right)$

$S D=\sqrt{\frac{\sum_{i=1}^{n}\left(x_{i}-\bar{x}\right)^{2}}{n-1}}$

here, $n$ is the number of experimental data, $y_{e i}$ is the experimental CPME yield, $y_{p i}$ is the predicted CPME yield, and $y_{m}$ is the average CPME yield determined from experiments. In Eq. (13), $n$ represents the size of the dataset, and $\bar{x}$ represents the mean value of the dataset $x_{1}, \ldots, x_{n}$.

\subsection{Statistical analysis}

The performance of the ELM model was assessed based on the coefficient of determination $\left(R^{2}\right)$ and root mean square error (RMSE):

$R^{2}=1-\sum_{i=1}^{n}\left(\frac{\left(y_{e i}-y_{p i}\right)^{2}}{\left(y_{m}-y_{p i}\right)^{2}}\right)$

$R M S E=\sqrt{\frac{1}{n} \sum_{i=1}^{n}\left(y_{p i}-y_{e i}\right)^{2}}$

where $n$ is the number of experimental data, $y_{e i}$ is the experimental CPME yield, $y_{p i}$ is the predicted CPME yield, and $y_{m}$ is the average CPME yield determined from experiments. The accuracy of the model was determined based on the $R^{2}$ value and RMSE. The smaller the RMSE and the higher the $R^{2}$ value, the higher the accuracy of the model. The $R^{2}$ value should not be less than $80 \%$ [44].

\subsection{Sensitivity analysis}

Sensitivity analysis is a method employed to determine sensitivity of an outcome (which in this case is the methyl ester conversion yield) to the input parameters. Sensitivity analysis is carried out to determine (1) which parameters require additional research to strengthen the knowledge base, which will reduce output uncertainty, (2) which parameters are insignificant and can be eliminated from the final model, (3) which inputs or parameters have a significant effect that will determine output variability, (4) which parameters are strongly correlated with the output, and (5) once the model is used for production, what are the consequences or results from changing a given input parameter [45]. In this study, Eq. (16) proposed by Garson (1991) was used to measure the level of significance of input variables for CPME, which is based on the partition of weights: 


$$
p q=\frac{\sum_{r=1}^{r=M_{c}}\left(\left(\left|W_{q r}^{p c}\right| / \sum_{d=1}^{M_{p}}\left|W_{d r}^{p c}\right|\right) \times\left|W_{r s}^{c b}\right|\right)}{\sum_{d=1}^{d=M_{p}}\left\{\sum_{r=1}^{r=M_{c}}\left(\left|W_{d r}^{p c}\right| / \sum_{d=1}^{M_{p}}\left|W_{d r}^{p c}\right|\right) \times\left|W_{r s}^{c b}\right|\right\}}
$$

where $p q$ is the relative significance of the $q c$ input variable on the output variable, $M_{p}$ and $M_{c}$ represent the number of input neurons and hidden neurons respectively, and $W$ represents the connection weights. It shall be noted that the superscripts $p, b$, and $c$ represent the input, output and hidden layers respectively, whereas the subscripts $d, s$, and $r$ represent the input, output and hidden neurons respectively.

\subsection{Fuel properties}

The physicochemical properties of the CPME produced by microwave irradiation-assisted transesterification using the optimum process parameters were measured. The physicochemical properties (kinematic viscosity, density, acid value, heating value, oxidation stability, flash point, pour point, cloud point, and copper strip corrosion) were determined according to ASTM D6751 and EN 14214 standard test methods and they (the properties) were compared with those for diesel. The FAME content was measured by referring to the EN 14103:2011 standard test method. The FAME content is expressed as:

$\mathrm{FAME}=\frac{\sum A-A_{C 19}}{A_{C 19}} \times \frac{W_{C 19}}{W} \times 100$

where FAME represents the fatty acid methyl ester content in percent by mass $(\%(\mathrm{~m} / \mathrm{m})), \sum A$ is the total peak area from methyl ester $C_{6: 0}$ to methyl ester $C_{24: 1}, A_{C 19}$ is the peak area corresponding to methyl nanodecanoate $\left(C_{19}\right), W_{C 19}$ is the weight, in milligrams $(\mathrm{mg})$, of methyl nanodecanoate $\left(\mathrm{C}_{19}\right)$, which is used as the internal standard, and $W$ is the weight, in milligrams (mg), of the methyl ester produced in this study.

The glycerol and glyceride contents were identified based on the EN 14105:2011 standard method, as expressed by the following equations:

Monoglycerides $(\%(\mathrm{~m} / \mathrm{m})), M=\left(\frac{A_{M}}{A_{M C 19}}\right) \times\left(\frac{M_{M C 19}}{m}\right) \times 100$

Diglycerides $(\%(\mathrm{~m} / \mathrm{m})), D=\left(\frac{A_{D}}{A_{D C 38}}\right) \times\left(\frac{M_{D C 38}}{m}\right) \times 100$

Triglycerides $(\%(\mathrm{~m} / \mathrm{m})), T=\left(\frac{A_{T}}{A_{T C 57}}\right) \times\left(\frac{M_{T C 57}}{m}\right) \times 100$

Free glycerol $(\%(\mathrm{~m} / \mathrm{m})), G=\left[a_{G}\left(\frac{A_{G}}{A_{E I 1}}\right)+b_{G}\right] \times\left(\frac{M_{E I}}{m}\right) \times 100$

Total glycerol $(\%(\mathrm{~m} / \mathrm{m}))=G+0.255 M+0.146 D+0.103 T$

where $A_{M}, A_{D}$, and $A_{T}$ are the sum of the peak areas of the monoglycerides, diglycerides, and triglycerides respectively, $A_{M C 19}$ is the area of the internal standard monoglycerides $C_{19}, M_{M C 19}$ is the weight, in milligrams ( $\mathrm{mg}$ ), of the internal standard monoglycerides $C_{19}, A_{D C 38}$ is the peak area of internal standard $C_{38}, M_{D C 38}$ is the weight, in milligrams ( $\mathrm{mg}$ ), of the internal standard diglycerides $C_{38}, A_{T C 57}$ is the area of the internal standard triglycerides $C_{57}, M_{T C 57}$ is the weight, in milligrams ( $\mathrm{mg}$ ), of internal standard triglycerides $C_{57}$. In addition, $m$ is the weight, in milligrams (mg), of the biodiesel sample, $a_{G}$ and $b_{G}$ are the regression coefficients of the calibration function of glycerol, $A_{G}$ is the peak area of glycerol, $A_{E I 1}$ is the peak of internal standard 1,2,4butanetriol, and $M_{E I}$ is the weight, in milligrams ( $\mathrm{mg}$ ), of the internal standard 1,2,4-butanetriol.

\section{Results and discussion}

\subsection{Effect of reaction time on acid value}

The effect of reaction time on acid value of the esterified Ceiba pentandra oil is shown in Fig. 4. It can be seen that the acid value is lowest ( $1.878 \mathrm{mg} \mathrm{KOH} / \mathrm{g}$ ) at a reaction time of $300 \mathrm{~s}$. The presence of $\mathrm{H}_{2} \mathrm{SO}_{4}$ catalyst at longer reaction times (300-360 s) results in a slow equilibrium reaction due to undesirable side reactions, which is evidenced by a slight increase in acid value. Ma et al. [46] found that microwave irradiation was able to convert $37 \%-78 \%$ of the free fatty acids (FFAs) whereas in this study, $69-88 \%$ of the FFAs were converted. Kim et al. [47] found that microwave irradiation improved the conversion of FFAs from $39.9 \%$ to $66.1 \%$. Lieu et al. [48] undertook a kinetics study on microwave irradiation-assisted esterification of FFAs from CCPO. Their results showed range of acid values of the esterified Ceiba pentandra oil was $0.776-4.529 \mathrm{mg} \mathrm{KOH} / \mathrm{g}$. This indicates that microwave irradiation has the potential to reduce the FFAs in the esterified oil to the desired acid value $(1.878 \mathrm{mg} \mathrm{KOH} / \mathrm{g}$ ).

\subsection{ELM model}

The ELM is a modeling technique used to predict and solve various types of engineering problems. It is a single-hidden-layer feedforward neural network where the parameters of the hidden layer are randomly generated [49]. The ELM can calculate the output weights analytically using the Moore-Penrose generalized inverse. Therefore, ELM is advantageous because of its breakneck learning speed and better generalization capability [15]. However, the main disadvantage of ELM is that it requires trial and error to determine the optimal ELM architecture. The trial-and-error procedure is very time-consuming and tedious. The randomness of the input weights can also reduce effectiveness of the algorithm and influences the algorithm performance such that the ELM output is not really stable [50-52]. The CPME yield values predicted by the ELM model for various combinations of transesterification process

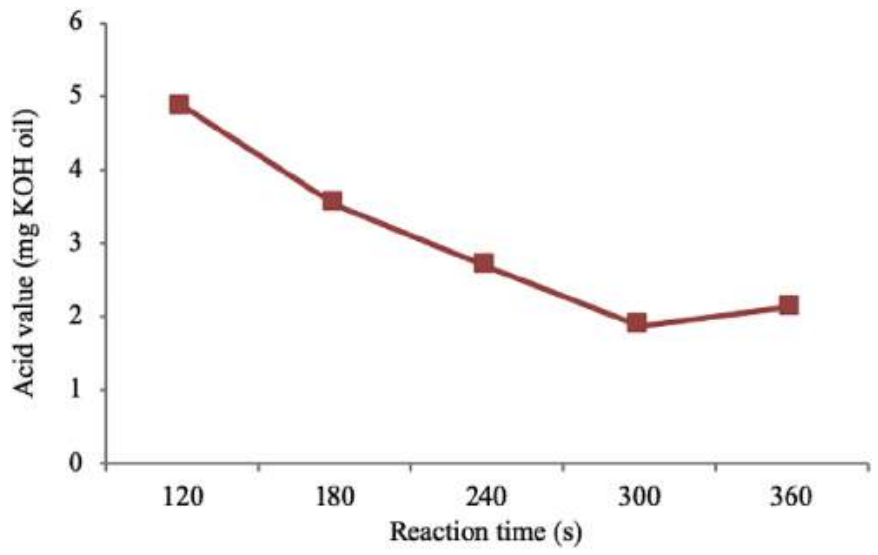

Fig. 4. Effect of reaction time on acid value of esterified Ceiba pentandra oil. 
parameters are shown in Table 3. Fig. 5 shows the $R$ values obtained by the ELM model for training, testing, and overall datasets are $0.999,0.986$, and 0.996 respectively. It can be seen the $R$ values are all close to 1.000 , indicating that there is good correlation between the experimental and predicted values. The $R^{2}$ value and RMSE were 0.992 and 0.142 respectively, as shown in Table 2. The RMSE indicates the goodness of fit and it should be as low as possible because it represents the standard deviation of the residuals of the regression model [53]. Fig. 4 shows the comparison between the CPME yield values predicted by ELM model and those obtained from experiments. It can be observed ELM model is able to predict CPME yield remarkably well, indicating the former is a reliable method to predict the latter (see Fig. 6).

\subsection{Random sub-sampling cross validation for ELM model}

A total of 23 datasets were used for training while the remaining six datasets were used for testing. The process was repeated ten times using various combinations of inputs with the same userdefined parameters, as shown in Table 4. Based on the results, the $\mathrm{AAD}$ and $\mathrm{SD}$ of the random sub-sampling cross validation are 0.00587 and 0.0026 respectively, indicating accuracy of the ELM model.

\subsection{Optimization of transesterification process parameters}

The optimum process parameters for microwave irradiationassisted transesterification in order to maximize the CPME yield obtained from the ELM-CS model are as follows: (1) methanol/oil ratio: $60 \%$, (2) $\mathrm{KOH}$ catalyst concentration: $0.84 \%(\mathrm{w} / \mathrm{w}),(3)$ stirring speed: $800 \mathrm{rpm}$, and (4) reaction time: $388 \mathrm{~s}$. The corresponding optimal CPME yield predicted by the ELM-CS model is $96.19 \%$. The optimum conditions predicted by the model were verified by carrying out three independent experimental replicates using the

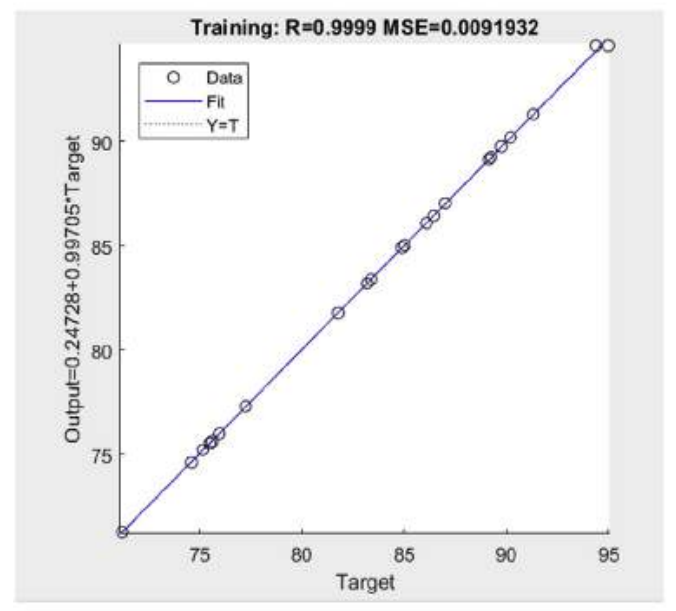

(a)

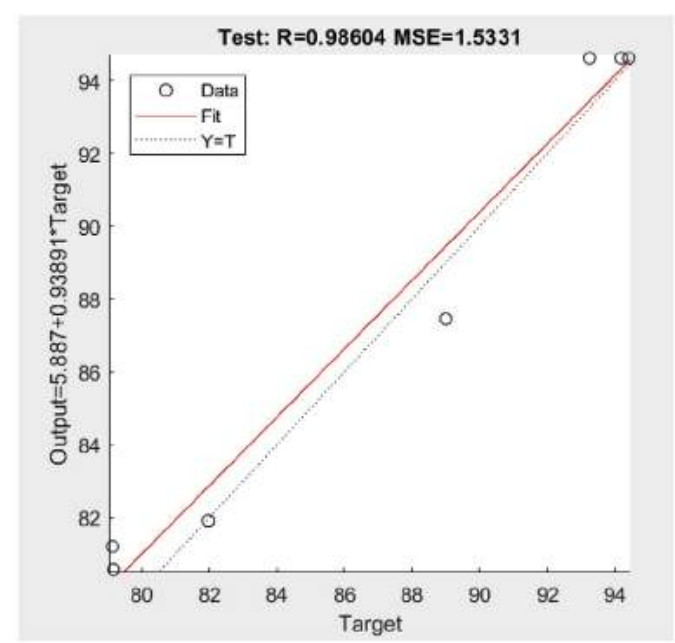

(b)

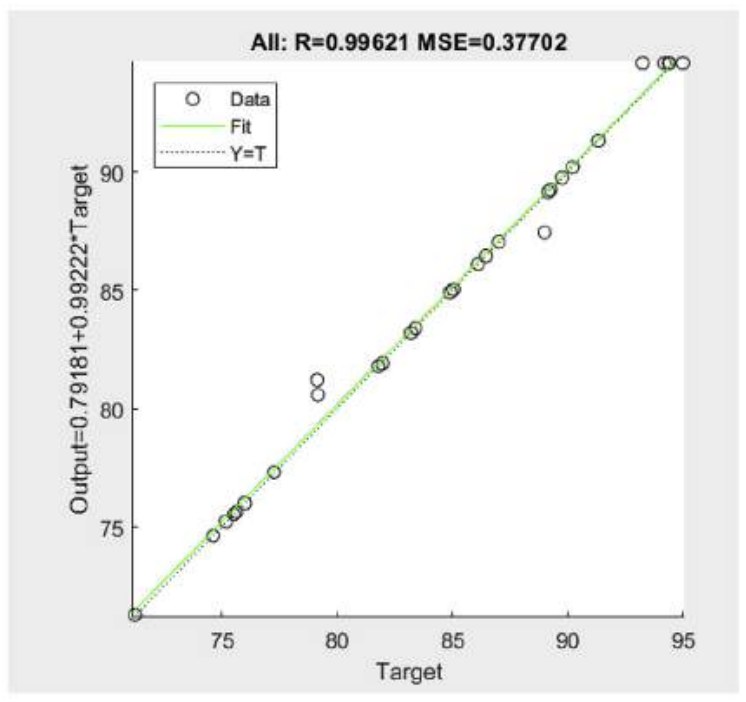

(c)

Fig. 5. Correlation between output and target values for (a) training dataset, (b) testing dataset, and (c) overall dataset. 


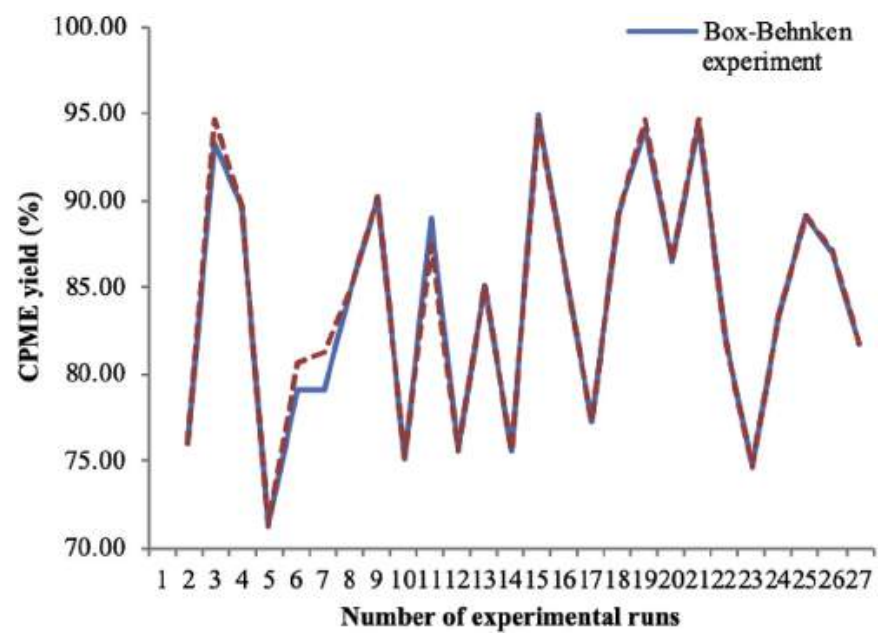

Fig. 6. Comparison of the CPME yield predicted by ELM model and CPME yield obtained from Box-Behnken experiment.

Table 4

Results of the random sub-sampling cross validation.

\begin{tabular}{ll}
\hline Repetition & AAD \\
\hline Repeat 1 & 0.00455 \\
Repeat 2 & 0.00512 \\
Repeat 3 & 0.00500 \\
Repeat 4 & 0.00320 \\
Repeat 5 & 0.00551 \\
Repeat 6 & 0.00363 \\
Repeat 7 & 0.01280 \\
Repeat 8 & 0.00713 \\
Repeat 9 & 0.00703 \\
Repeat 10 & 0.00477 \\
\hline Overall average & 0.00587 \\
SD & 0.00260 \\
\hline
\end{tabular}

optimum transesterification process parameters and average CPME yield was determined. The actual CPME yield obtained from the experiments using the microwave reactor is slightly lower, with a value of $95.42 \%$. Since there is good agreement between the predicted and experimental CPME yield, this indicates that ELM model is capable of predicting the CPME yield with high accuracy.

\subsection{Sensitivity analysis of the transesterification reaction parameters}

Various combinations of inputs were used to determine the effect of each input parameter on the output of ELM model. Fig. 7 shows the level of significance of the input variables on the CPME yield. It can be observed the stirring speed has the most significant effect on CPME yield (25.62\%), followed by reaction time (25.19\%), and $\mathrm{KOH}$ catalyst concentration (25.05\%). The methanol/oil ratio has the least significant effect, with a value of $24.15 \%$.

\subsection{Combined effects of the transesterification reaction parameters}

Three-dimensional response surface plots were plotted in order to examine the combined effect of the transesterification process parameters on CPME yield, as shown in Fig. 8a-d. In general, CPME yield increases as the stirring speed, reaction time, $\mathrm{KOH}$ catalyst concentration, and methanol/oil ratio increase up to a certain value, and then decreases thereafter. Fig. 8a shows the combined effect of stirring speed and reaction time on CPME yield, and it can be seen

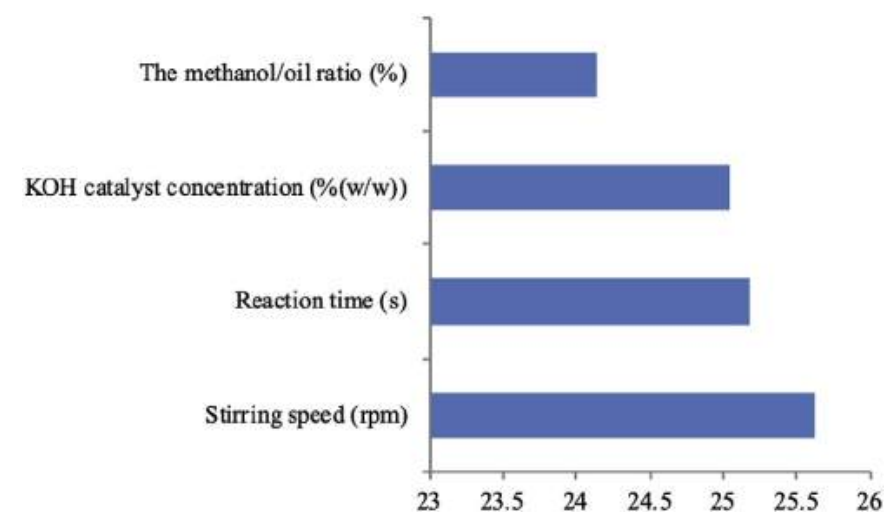

Fig. 7. Level of significance of input variables, indicating effect of each input variable on CPME yield.

that increasing the stirring speed and reaction time up to a certain point boosts it. The CPME yield is higher at higher stirring speeds and at longer reaction times. The highest CPME yield was $96.19 \%$, obtained when the stirring speed and reaction time were $800 \mathrm{rpm}$ and $388 \mathrm{~s}$ respectively. A higher stirring speed promotes the reaction between methanol and esterified oil which boosts CPME yield. Likewise, a longer reaction time ensures complete transesterification reaction, which boosts CPME yield. Fig. 8b shows the combined effects of reaction time and $\mathrm{KOH}$ catalyst concentration on CPME yield. The highest CPME yield was achieved when the reaction time and $\mathrm{KOH}$ catalyst concentration are $388 \mathrm{~s}$ and $0.84 \%(w / w)$ respectively. It can be observed the effect of $\mathrm{KOH}$ catalyst concentration was more pronounced at higher reaction times. This indicates the reactants (methanol, esterified Ceiba pentandra oil, and $\mathrm{KOH}$ catalyst) require a specific duration to ensure a homogeneous mixture, and which will increase CPME yield. This shows the reaction time and $\mathrm{KOH}$ catalyst concentration have a pronounced effect on the CPME yield. Fig. 8c shows the combined effect of $\mathrm{KOH}$ catalyst concentration and methanol/oil ratio on CPME yield. It can be seen CPME yield reaches its maximum when the methanol/oil ratio is within a range of $50-60 \%$. A methanol/oil ratio of more than $60 \%$ has a moderate effect on CPME yield. It can be seen the $\mathrm{KOH}$ catalyst concentration determines CPME yield. The CPME yield slowly decreases when the $\mathrm{KOH}$ catalyst concentration increases beyond the optimal value of $0.84 \%(\mathrm{w} / \mathrm{w})$. Hence, the $\mathrm{KOH}$ catalyst concentration is one of the important parameters that need to be controlled in order to attain a high CPME yield. High concentrations of $\mathrm{KOH}$ catalyst will result in emulsification and saponification of CPME during the purification process [54]. Fig. 8d shows combined effect of the stirring speed and methanol/oil ratio on CPME yield. The highest CPME yield (96.19\%) was attained when the methanol/oil ratio and stirring speed were $60 \%$ and $800 \mathrm{rpm}$ respectively. It is clear both stirring speed and methanol/oil ratio have a significant effect on the CPME yield. The CPME yield increases from $82.50 \%$ to $96.19 \%$ as the stirring speed increases from $600 \mathrm{rpm}$ to $800 \mathrm{rpm}$. It is important to use the optimum stirring speed setting to ensure homogeneous mixing of methanol, $\mathrm{KOH}$ catalyst, and esterified Ceiba pentandra oil in order to achieve a complete transesterification process. In addition, it is important to ensure a suitable methanol/oil ratio in order to optimize the transesterification process. If the amount of methanol in the mixture is too low, this will produce more monoglycerides and diglycerides compared with methyl ester. In contrast, if the amount of methanol in the mixture is too high, this will lead to solubility of the by-product (glycerol) in the mixture, which will complicate the separation of methyl ester and by- 


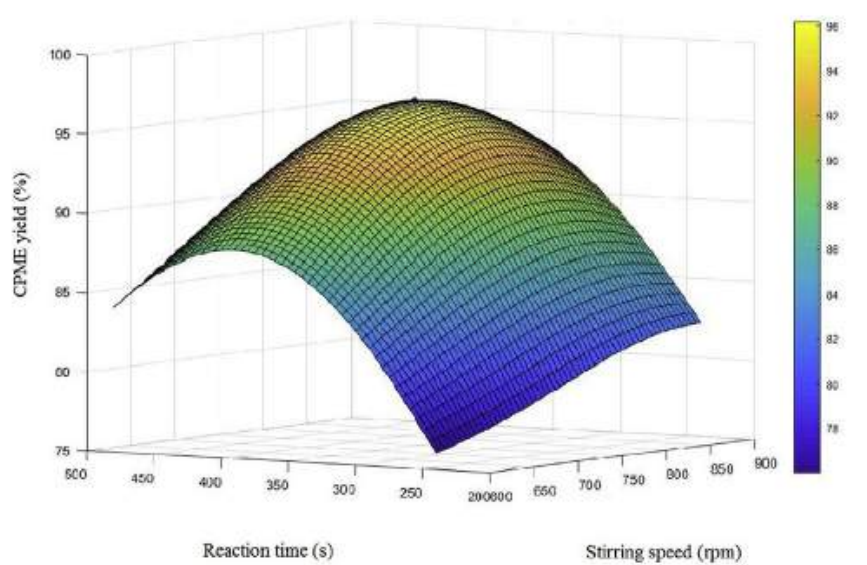

(a)

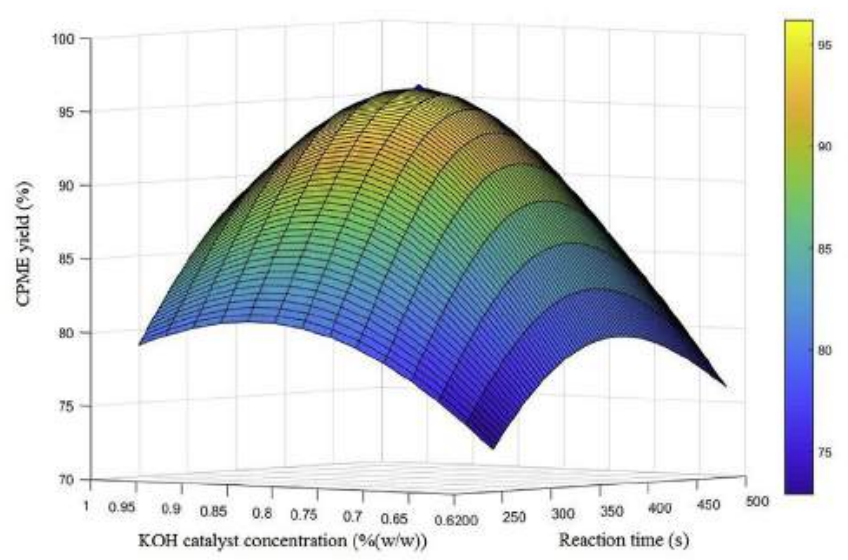

(b)

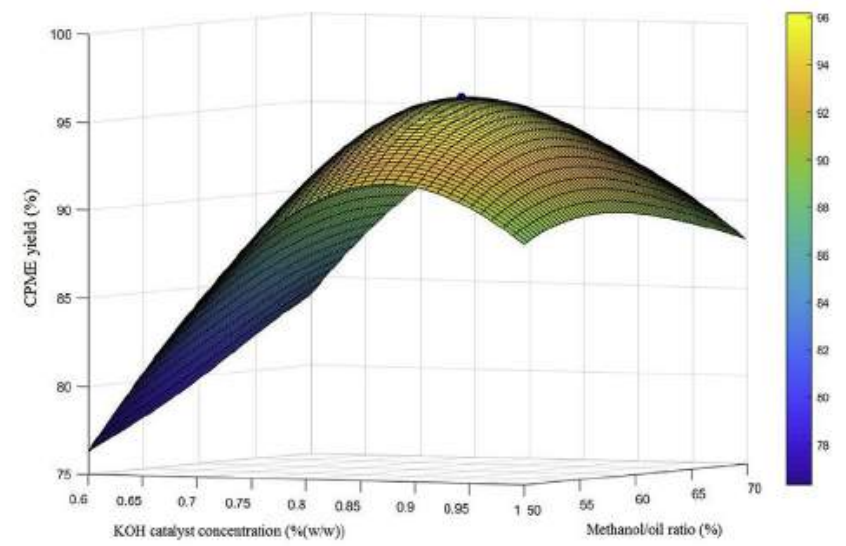

(c)

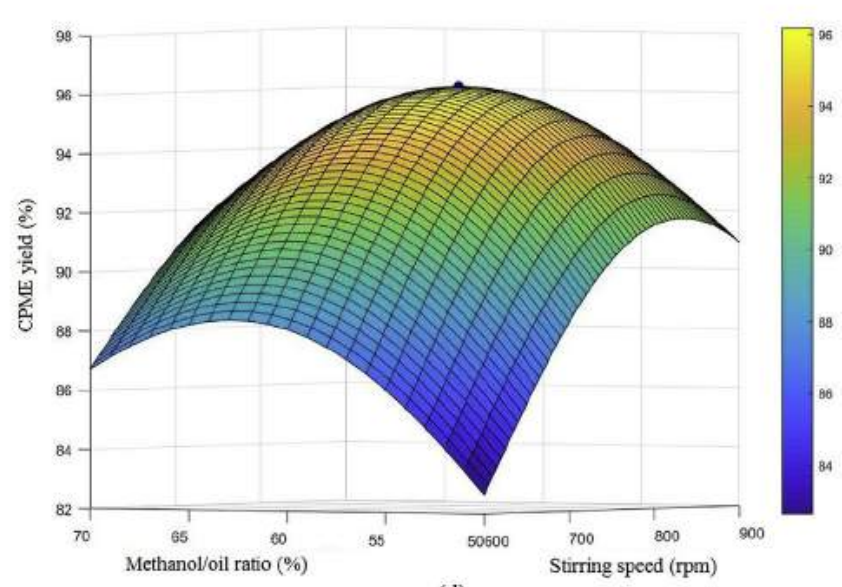

(d)

Fig. 8. (a-d) Three-dimensional response surface plots showing the combined effect of the transesterification process parameters on CPME yield.

product. It is crucial to use an appropriate amount of methanol because the microwave reactor is a closed system. Microwave irradiation-assisted transesterification does not allow excessive amounts of methanol in the transesterification process and therefore, the amount of methanol must be definite in order to boost CPME yield.

\subsection{Model validation}

In order to validate the prediction of optimal CPME yield, experiments were carried out in triplicate using the optimum microwave irradiation-assisted transesterification process parameters, and the results are summarized in Table 5 . The average CPME yield is $95.42 \%$ with a standard deviation of 0.003 . This indicates a very good agreement between the optimum CPME yield predicted by the ELM-CS model and the average CPME yield obtained from the experiments. Based on the results, it can be deduced the model is reliable and it is able to predict the optimal conditions of the microwave irradiation-assisted transesterification process.

\subsection{Physicochemical properties of CCPO and CPME}

The physicochemical properties of CCPO and CPME, such as kinematic viscosity at $40^{\circ} \mathrm{C}$, density at $15^{\circ} \mathrm{C}$, cloud point, pour point, flash point, acid value, calorific value, oxidation stability, and FAME, glyceride, and glycerol contents were measured according to ASTM D6751 and EN 14214 standard test methods and the results are tabulated in Table 6. Kinematic viscosity is an important property of biodiesel and it is known that biodiesels have higher kinematic viscosities compared with diesel [55]. The kinematic viscosities of the CPCO and CPME were 18.74 and $4.69 \mathrm{~mm}^{2} / \mathrm{s}$ respectively, as seen in this study. The CPME has lower kinematic viscosity and acid value, higher heating value, and superior cold flow properties, indicating the advantages of producing biodiesel from Ceiba pentandra oil by microwave irradiation-assisted transesterification compared with conventional transesterification. It is well known acid values of both crude oil and methyl ester are influenced by the type of feedstock as well as the degree of refinement [56]. The high acid value of the CPME $(0.18 \mathrm{mg} \mathrm{KOH} / \mathrm{g})$ is significantly reduced by acid-catalyzed esterification and indeed, it is proven that the CPME has the lowest acid value after acid-catalyzed esterification and alkaline-catalyzed transesterification. The flash point of the CPME is $158.5^{\circ} \mathrm{C}$, which is significantly higher than the flash point specified in the ASTM D6751 standard $\left(130^{\circ} \mathrm{C}\right)$. A higher flash point of CPME is desirable because this will reduce the risk of fire hazards, which is a primary concern when handling, transporting, and storing fuels [57]. However, the calorific value of CPME (40.276 MJ/ $\mathrm{kg}$ ) was higher in this study compared with those obtained by earlier researchers due to the composition of saturated and 
Table 5

CPME yield obtained from microwave irradiation-assisted transesterification process using the optimum process parameters.

\begin{tabular}{|c|c|c|c|c|c|}
\hline Run & Reaction time (s) & $\mathrm{KOH}$ catalyst concentration (wt\%) & Methanol/oil ratio (\%) & Stirring speed (rpm) & CPME yield (\%) \\
\hline 1 & 388 & 0.84 & 60 & 800 & 95.82 \\
\hline 2 & 388 & 0.84 & 60 & 800 & 94.91 \\
\hline 3 & 388 & 0.84 & 60 & 800 & 95.54 \\
\hline \multicolumn{5}{|c|}{ Average experimental CPME yield (\%) } & 95.42 \\
\hline \multicolumn{5}{|c|}{ Predicted optimum CPME yield (\%) } & 96.19 \\
\hline \multicolumn{5}{|l|}{ SD } & 0.003 \\
\hline
\end{tabular}

Table 6

Physicochemical properties of CCPO and CPME.

\begin{tabular}{|c|c|c|c|c|c|c|}
\hline Properties & Unit & Standard test method & $\mathrm{CCPO}^{\mathrm{a}}$ & $\mathrm{CPME}^{\mathrm{a}}$ & CPME [7] & Diesel $^{2}$ \\
\hline Density at $15^{\circ} \mathrm{C}$ & $\mathrm{kg} / \mathrm{m}^{3}$ & D1298 & 906.5 & 883.6 & 875 & 826 \\
\hline Kinematic viscosity at $40^{\circ} \mathrm{C}$ & $\mathrm{mm}^{2} / \mathrm{s}$ & D445 & 18.74 & 4.69 & 5.4 & 2.99 \\
\hline Flash point & ${ }^{\circ} \mathrm{C}$ & D93 & 186.5 & 158.5 & 156 & 72.5 \\
\hline Pour point & ${ }^{\circ} \mathrm{C}$ & D97 & - & -2.0 & - & -5 \\
\hline Cloud point & ${ }^{\circ} \mathrm{C}$ & D2500 & - & -3.0 & - & -8 \\
\hline Calorific value & $\mathrm{MJ} / \mathrm{kg}$ & EN 14214 & 38.672 & 40.276 & 36.292 & 45.483 \\
\hline Copper strip corrosion & - & D130 & - & $1 \mathrm{a}$ & $1 \mathrm{a}$ & $1 \mathrm{a}$ \\
\hline Oxidation stability & $\mathrm{h}$ & EN 14112 & 4.8 & 9.82 & - & 23.9 \\
\hline Acid value & $\mathrm{mg} \mathrm{KOH} / \mathrm{g}$ & D 664 & 16.2 & 0.18 & - & 0.06 \\
\hline FAME content & $\%(\mathrm{~m} / \mathrm{m})$ & $\begin{array}{l}\text { EN } \\
14103: 2011\end{array}$ & & 98.96 & & \\
\hline Monoglycerides & $\%(\mathrm{~m} / \mathrm{m})$ & EN14105 & - & 0.419 & - & - \\
\hline Diglycerides & $\%(\mathrm{~m} / \mathrm{m})$ & EN14105 & - & 0.108 & - & - \\
\hline Triglycerides & $\%(\mathrm{~m} / \mathrm{m})$ & EN14105 & - & 0.115 & - & - \\
\hline Free glycerol & $\%(\mathrm{~m} / \mathrm{m})$ & EN14105 & - & 0.017 & - & - \\
\hline Total glycerol & $\%(\mathrm{~m} / \mathrm{m})$ & EN14105 & - & 0.136 & - & - \\
\hline
\end{tabular}

${ }^{\text {a }}$ Values measured in this study.

unsaturated fatty acids of CPME. The CPME has a relatively high oxidation stability $(9.82 \mathrm{~h})$, which is likely due to its higher amounts of saturated carbon chains which will increase the induction time of oxidation. Small amounts of unsaturated carbon chains will have a significant effect on oxidation stability [58,59]. In general, a high oxidation stability is favorable because this will reduce the likelihood of biodiesel to oxidize over an extended period. This property is essential for fuel storage and handling. Moreover, there is a high possibility the fuel will oxidize and deteriorate in the fuel tank and engine owing to high-temperature conditions and therefore, it is crucial for the fuel to have higher oxidation stability $[58,60]$. In addition, it is desirable for biodiesels to have higher oxidation stability because this will facilitate the supply and distribution of biodiesels to remote areas located far from biodiesel production facilities. The oxidation stability enhancement is likely due to the stearic and myristic fatty acid content of FAME [61]. Biodiesel consists of ester molecules, which tend to hydrolyze into alcohol and acid in the presence of air or oxygen [62]. The presence of alcohol reduces the flash point whereas the presence of acid increases its (acid) value [63]. In contrast, a higher polyunsaturated fatty acid content will improve the cold flow properties, but the resultant biodiesel is more susceptible to oxidation $[64,65]$. The FAME of CPME obtained in this study was $98.96 \%(\mathrm{~m} / \mathrm{m})$, which indicates the biodiesel produced is of very high quality. The monoglycerides, diglycerides, and triglycerides found in CPME were $0.42,0.11$, and $0.11 \%(\mathrm{~m} / \mathrm{m})$ respectively, which are below permissible limits of $0.8,0.2$, and $0.2 \%(\mathrm{~m} / \mathrm{m})$ respectively. Total glycerol found in the methyl ester was 0.14 , which was below the permissible limit of 0.25 . Results showed microwave irradiation had successfully reduced the amounts of monoglycerides, diglycerides, and triglycerides to acceptable levels. This indicate that microwave irradiation is able to enhance the conversion of methyl ester and minimize the concentrations of glycerides and glycerol.

\subsection{FTIR spectrum of the CPME}

The functional groups of the CPME were determined using FTIR spectroscopy. Fig. 9 shows the FTIR spectrum of the CPME, which provides insight on the oil-to-methyl ester conversion process. The FTIR spectrum shows the wavenumber at which the absorption peak occurs, functional group, type of vibration, and absorption intensity. It can be inferred from FTIR spectrum CPME is composed of long-chain FAMEs. There are three bands attributed to the bonds in $\mathrm{COOH}$ functional group, indicating the presence of carboxylates. The peaks at 2986, 2923, and $2853 \mathrm{~cm}^{-1}$ correspond to $\mathrm{C}-\mathrm{H}$, vinylic/olefinic $(\mathrm{C}-\mathrm{H})$ and alcohol group $(\mathrm{OH}, \mathrm{H}-$ bond $)$ respectively. The peaks at $1169-1566 \mathrm{~cm}^{-1}$ correspond to the bending vibrations of the methyl, methylene hydrocarbon, and unsaturated $\mathrm{C}-\mathrm{C}$ bonds respectively. The peak at $858 \mathrm{~cm}^{-1}$ indicates shear vibration of $\mathrm{C}-\mathrm{O}$ whereas the peak at $720 \mathrm{~cm}^{-1}$ indicates rockingbending vibration of the methylene group. The characteristic peak at $1724 \mathrm{~cm}^{-1}$ with strong absorption intensity is ascribed to the carbonyl group of methyl ester $\left(-\mathrm{CO}-\mathrm{OCH}_{3}\right)$. The results indicate CPME synthesis is successful.

\subsection{Advantages and disadvantages of microwave irradiation}

Microwave irradiation is a well-established method of accelerating and enhancing chemical reactions because it delivers the energy directly to the reactants [66]. Therefore, heat transfer is more effective than conventional heating and its reaction time is much shorter, lower oil/methanol ratio, and less energy consumption. Microwave irradiation accelerates the reaction and makes the separation process easier compared with conventional heating [34]. The optimum parameters of the microwave irradiation-assisted transesterification process conditions obtained are as follows: (1) methanol/oil ratio: $60 \%$, (2) $\mathrm{KOH}$ catalyst concentration: $0.84 \%(\mathrm{w} / \mathrm{w}),(3)$ stirring speed: $800 \mathrm{rpm}$, and (4) 


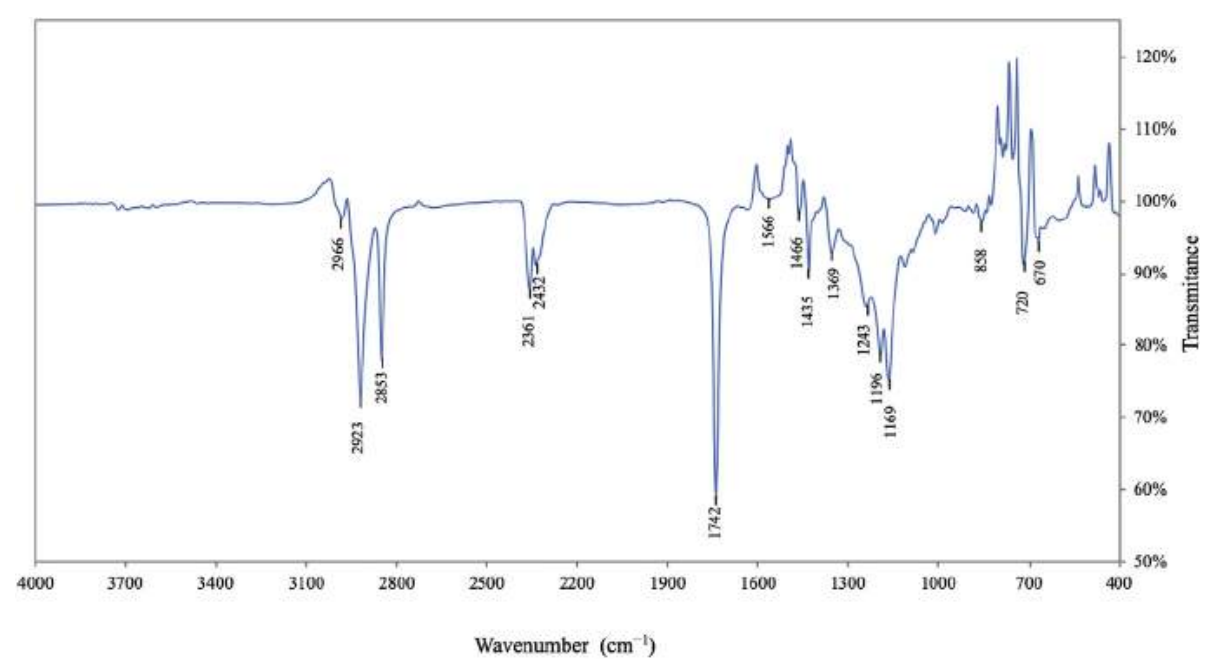

Fig. 9. FTIR spectrum of the CPME.

reaction time: $388 \mathrm{~s}$. The corresponding CPME yield is 96.19\%. Three independent experiments were conducted using the optimum process parameters and the average biodiesel yield is found to be $95.42 \%$. The reaction time of $388 \mathrm{~s}$ in this study was significantly shorter than that of Ponappa et al. [67], who optimized biodiesel production from Ceiba pentandra oil (kapok seed oil) using response surface methodology assisted by ultrasonic energy, where the reaction time was $32.17 \mathrm{~min}$. Kusumo et al. [7] optimized the transesterification process of Ceiba pentandra oil using kernelbased extreme learning machine and artificial neural networks and the time required to complete the reaction was $108 \mathrm{~min}$. The microwave method requires a lower concentration of catalyst $(0.84 \%(\mathrm{w} / \mathrm{w}))$ compared with the ultrasound method $(1.55 \%(\mathrm{w} / \mathrm{w}))$ and conventional transesterification $(1 \%(\mathrm{w} / \mathrm{w}))$. However, the main disadvantage of microwave technology is uncontrolled heating due to poor understanding of the occurrence of dielectric phenomenon. In addition, there are safety issues concerning the use of microwave technology for biodiesel production, which makes it difficult to scale-up microwave irradiation-assisted transesterification for industrial production $[68,69]$.

\section{Conclusion}

In this study, Ceiba pentandra methyl ester was produced from microwave irradiation-assisted transesterification. The microwave reactor is suitable for small-scale synthesis of biodiesel which minimizes wastage of crude oil because the maximum allowable volume in the glass vial is $10-20 \mathrm{~mL}$ compared with a conventional heating reactor. An ELM-CS model was developed to optimize the transesterification process parameters in order to boost CPME yield. The predicted CPME yield was found to be $96.19 \%$, which showed very good agreement of the experiments (95.42\%). BoxBehnken design was used to obtain the best combination of methanol/oil ratio (60\%), $\mathrm{KOH}$ catalyst concentration $(0.84 \%(\mathrm{w} / \mathrm{w}))$, reaction time (388 s), and stirring speed ( $800 \mathrm{rpm})$. The FAME of the CPME was $98.96 \%$, which indicates high purity of methyl ester produced in this study. In addition, oxidation stability increased by twofold after the transesterification process and based on the cold flow properties, it can be deduced that the CPME can be used in cold climate countries. Statistical analysis was then conducted to verify the accuracy of ELM-CS model and the results showed the model is reliable to predict the optimal parameters for microwave irradiation-assisted transesterification, based on the high $R(0.996)$ and $R^{2}(0.992)$ values as well as low RMSE (0.142). In general, the ELM-CS model is capable of predicting the optimum process parameters in order to maximize CPME yield while minimizing overall biodiesel production cost associated with conventional trial and error experimental techniques. Based on the results obtained from the ELM-CS model, the optimum process parameters can be used for microwave irradiation-assisted transesterification regardless of the feedstock, producing biodiesels that fulfill the physicochemical properties stipulated in the ASTM D6751 and EN 14214 standards.

\section{Acknowledgments}

This research was supported by the Direktorat Jenderal Penguatan Riset dan Pengembangan Kementerian Riset, Teknologi dan Pendidikan Tinggi Republik Indonesia, (Grant no. 147/SP2H/LT/ DRPM/2019) and Politeknik Negeri Medan, Medan, Indonesia. It also received the financial support of AAIBE Chair of Renewable Energy (Grant no: 201801 KETTHA), and Universiti Tenaga Nasional Internal Grant (UNIIG 2017) (Grant no.: J510050691). The authors express their appreciation to Ministry of Education Malaysia and University of Malaya, Kuala Lumpur Malaysia, for funding this work under their FRGS-MRSA (MO014-2016).

\section{Appendix A. Supplementary data}

Supplementary data to this article can be found online at https://doi.org/10.1016/j.renene.2019.07.065.

\section{References}

[1] M. Faried, M. Samer, E. Abdelsalam, R.S. Yousef, Y.A. Attia, A.S. Ali, Biodiesel production from microalgae: processes, technologies and recent advancements, Renew. Sustain. Energy Rev. 79 (2017) 893-913.

[2] S. Dharma, H.C. Ong, H.H. Masjuki, A.H. Sebayang, A.S. Silitonga, An overview of engine durability and compatibility using biodiesel-bioethanol-diesel blends in compression-ignition engines, Energy Convers. Manag. 128 (2016) $66-81$.

[3] W.N.M. Wan Ghazali, R. Mamat, H.H. Masjuki, G. Najafi, Effects of biodiesel from different feedstocks on engine performance and emissions: a review, Renew. Sustain. Energy Rev. 51 (2015) 585-602.

[4] M. Shahabuddin, A.M. Liaquat, H.H. Masjuki, M.A. Kalam, M. Mofijur, Ignition delay, combustion and emission characteristics of diesel engine fueled with biodiesel, Renew. Sustain. Energy Rev. 21 (2013) 623-632.

[5] J. Gupta, M. Agarwal, A.K. Dalai, Optimization of biodiesel production from mixture of edible and nonedible vegetable oils, Biocatal. Agric. Biotechnol. 8 (2016) 112-120 
[6] A. Woinaroschy, Multiobjective optimal design for biodiesel sustainable production, Fuel 135 (2014) 393-405.

[7] F. Kusumo, A.S. Silitonga, H.H. Masjuki, H.C. Ong, J. Siswantoro, T.M.I. Mahlia, Optimization of transesterification process for Ceiba pentandra oil: a comparative study between kernel-based extreme learning machine and artificial neural networks, Energy 134 (2017) 24-34.

[8] S. Dharma, M.H. Hassan, H.C. Ong, A.H. Sebayang, A.S. Silitonga, F. Kusumo, J. Milano, Experimental study and prediction of the performance and exhaust emissions of mixed Jatropha curcas-Ceiba pentandra biodiesel blends in diesel engine using artificial neural networks, J. Clean. Prod. 164 (2017) 618-633.

[9] A.H. Sebayang, H.H. Masjuki, H.C. Ong, S. Dharma, A.S. Silitonga, F. Kusumo, J. Milano, Optimization of bioethanol production from sorghum grains using artificial neural networks integrated with ant colony, Ind. Crops Prod. 97 (2017) 146-155.

[10] E. Betiku, S.S. Okunsolawo, S.O. Ajala, O.S. Odedele, Performance evaluation of artificial neural network coupled with generic algorithm and response surface methodology in modeling and optimization of biodiesel production process parameters from shea tree (Vitellaria paradoxa) nut butter, Renew. Energy 76 (2015) 408-417.

[11] G.R. Moradi, S. Dehghani, F. Khosravian, A. Arjmandzadeh, The optimized operational conditions for biodiesel production from soybean oil and application of artificial neural networks for estimation of the biodiesel yield, Renew. Energy 50 (2013) 915-920.

[12] M.S. Ismail, M. Moghavvemi, T. Mahlia, Genetic algorithm based optimization on modeling and design of hybrid renewable energy systems, Energy Convers. Manag. 85 (2014) 120-130.

[13] H.C. Ong, H. Masjuki, T. Mahlia, A. Silitonga, W. Chong, K. Leong, Optimization of biodiesel production and engine performance from high free fatty acid Calophyllum inophyllum oil in CI diesel engine, Energy Convers. Manag. 81 (2014) 30-40.

[14] A.H. Sebayang, H.H. Masjuki, H.C. Ong, S. Dharma, A.S. Silitonga, F. Kusumo, J. Milano, Prediction of engine performance and emissions with Manihot glaziovii bioethanol - Gasoline blended using extreme learning machine, Fuel 210 (2017) 914-921.

[15] K.I. Wong, P.K. Wong, C.S. Cheung, C.M. Vong, Modeling and optimization of biodiesel engine performance using advanced machine learning methods, Energy 55 (2013) 519-528.

[16] S. Dharma, H.H. Masjuki, H.C. Ong, A.H. Sebayang, A.S. Silitonga, F. Kusumo, T.M.I. Mahlia, Optimization of biodiesel production process for mixed Jatropha curcas-Ceiba pentandra biodiesel using response surface methodology, Energy Convers. Manag. 115 (2016) 178-190.

[17] N. Damanik, H.C. Ong, W. Chong, A. Silitonga, Biodiesel Production from Calophyllum Inophyllum- Palm Mixed Oil, Energy Sources, Part A: Recovery, Utilization, and Environmental Effects, 2017, pp. 1-7.

[18] F. Kusumo, A. Silitonga, H.C. Ong, H. Masjuki, T. Mahlia, A Comparative Study of Ultrasound and Infrared Transesterification of Sterculia Foetida Oil for Biodiesel Production, Energy Sources, Part A: Recovery, Utilization, and Environmental Effects, 2017, pp. 1-8.

[19] L.F. Chuah, J.J. Klemeš, S. Yusup, A. Bokhari, M.M. Akbar, A review of cleaner intensification technologies in biodiesel production, J. Clean. Prod. 146 (2017) $181-193$.

[20] L. Dehghan, M.-T. Golmakani, S.M.H. Hosseini, Optimization of microwaveassisted accelerated transesterification of inedible olive oil for biodiesel production, Renew. Energy 138 (2019) 915-922.

[21] M.G. Nayak, A.P. Vyas, Optimization of microwave-assisted biodiesel production from Papaya oil using response surface methodology, Renew. Energy 138 (2019) 18-28.

[22] A. Silitonga, H. Masjuki, T. Mahlia, H. Ong, A. Atabani, W. Chong, A global comparative review of biodiesel production from Jatropha curcas using different homogeneous acid and alkaline catalysts: study of physical and chemical properties, Renew. Sustain. Energy Rev. 24 (2013) 514-533.

[23] P. Verma, M.P. Sharma, Review of process parameters for biodiesel production from different feedstocks, Renew. Sustain. Energy Rev. 62 (2016) 1063-1071.

[24] S. Budžaki, G. Miljić, M. Tišma, S. Sundaram, V. Hessel, Is there a future for enzymatic biodiesel industrial production in microreactors? Appl. Energy 201 (2017) 124-134.

[25] W. Yang, J.F. Casey, Y. Gao, A new sample preparation method for crude or fuel oils by mineralization utilizing single reaction chamber microwave for broader multi-element analysis by ICP techniques, Fuel 206 (2017) 64-79.

[26] J.-Z. Liu, Q. Cui, Y.-F. Kang, Y. Meng, M.-Z. Gao, T. Efferth, Y.-J. Fu, Euonymus maackii Rupr seed oil as a new potential non-edible feedstock for biodiesel, Renew. Energy 133 (2019) 261-267.

[27] N. Azcan, O. Yilmaz, Microwave assisted transesterification of waste frying oil and concentrate methyl ester content of biodiesel by molecular distillation, Fuel 104 (2013) 614-619.

[28] A.R. Gupta, V.K. Rathod, Calcium diglyceroxide catalyzed biodiesel production from waste cooking oil in the presence of microwave: optimization and kinetic studies, Renew. Energy 121 (2018) 757-767.

[29] T. Chee Loong, A. Idris, One step transesterification of biodiesel production using simultaneous cooling and microwave heating, J. Clean. Prod. 146 (2017) $57-62$.

[30] I. Choedkiatsakul, K. Ngaosuwan, S. Assabumrungrat, S. Mantegna, G. Cravotto, Biodiesel production in a novel continuous flow microwave reactor, Renew. Energy 83 (2015) 25-29.

[31] Y.K. Walia, K. Kishore, D. Vasu, G. DK, Physico-chemical analysis of Ceiba pentandra (kapok), Int. J. Circuit Theory Appl. Sci. 1 (2009) 15-18.

32] A.E. Atabani, A.S. Silitonga, I.A. Badruddin, T.M.I. Mahlia, H.H. Masjuki, S. Mekhilef, A comprehensive review on biodiesel as an alternative energy resource and its characteristics, Renew. Sustain. Energy Rev. 16 (2012) 2070-2093.

[33] A.S. Silitonga, H.H. Masjuki, T.M.I. Mahlia, H.C. Ong, W.T. Chong, M.H. Boosroh, Overview properties of biodiesel diesel blends from edible and non-edible feedstock, Renew. Sustain. Energy Rev. 22 (2013) 346-360.

[34] J. Milano, H.C. Ong, H.H. Masjuki, A.S. Silitonga, W.-H. Chen, F. Kusumo, S. Dharma, A.H. Sebayang, Optimization of biodiesel production by microwave irradiation-assisted transesterification for waste cooking oil-Calophyllum inophyllum oil via response surface methodology, Energy Convers. Manag. 158 (2018) 400-415.

[35] L.A. Jermolovicius, L.C.M. Cantagesso, R.B. do Nascimento, E.R. de Castro, E.V. dos, S. Pouzada, J.T. Senise, Microwave fast-tracking biodiesel production, Chem. Eng. Process: Process Intensification 122 (2017) 380-388.

[36] S.A. El Sherbiny, A.A. Refaat, S.T. El Sheltawy, Production of biodiesel using the microwave technique, J. Adv. Res. 1 (2010) 309-314.

[37] P. Kundu, V. Paul, V. Kumar, I.M. Mishra, Formulation development, modeling and optimization of emulsification process using evolving RSM coupled hybrid ANN-GA framework, Chem. Eng. Res. Des. 104 (2015) 773-790.

[38] S. Wu, Y. Wang, S. Cheng, Extreme learning machine based wind speed estimation and sensorless control for wind turbine power generation system, Neurocomputing 102 (2013) 163-175.

[39] K.I. Wong, C.M. Vong, P.K. Wong, J. Luo, Sparse Bayesian extreme learning machine and its application to biofuel engine performance prediction, Neurocomputing 149 (2015) 397-404.

[40] A.S. Joshi, O. Kulkarni, G.M. Kakandikar, V.M. Nandedkar, Cuckoo search optimization- a review, Mater. Today: Proceedings 4 (2017) 7262-7269.

[41] X.-S. Yang, Nature-InspiredMeta-HeuristicAlgorithms, Luniver Press, 2010.

[42] X.-S. Yang, S. Deb, Engineering optimisation by cuckoo search, Int. J. Math. Model. Numer. Optim. 1 (2010) 330-343.

[43] C. Bindhu, J.R.C. Reddy, B.V.S.K. Rao, T. Ravinder, P.P. Chakrabarti, M.S.L. Karuna, R.B.N. Prasad, Preparation and evaluation of biodiesel from Sterculia foetida seed oil, J. Am. Oil Chem. Soc. 89 (2012) 891-896.

[44] P. Shivakumar, Pai Srinivasa, B.R. Shrinivasa Rao, Artificial Neural Network based prediction of performance and emission characteristics of a variable compression ratio $\mathrm{CI}$ engine using WCO as a biodiesel at different injection timings, Appl. Energy 88 (2011) 2344-2354.

[45] D.M. Hamby, A review of techniques for parameter sensitivity analysis of environmental models, Environ. Monit. Assess. 32 (1994) 135-154.

[46] L. Ma, E. Lv, L. Du, J. Lu, J. Ding, Statistical modeling/optimization and process intensification of microwave-assisted acidified oil esterification, Energy Convers. Manag. 122 (2016) 411-418.

[47] D. Kim, J. Choi, G.-J. Kim, S.K. Seol, S. Jung, Accelerated esterification of free fatty acid using pulsed microwaves, Bioresour. Technol. 102 (2011) 7229-7231.

[48] T. Lieu, S. Yusup, M. Moniruzzaman, Kinetic study on microwave-assisted esterification of free fatty acids derived from Ceiba pentandra Seed Oil, Bioresour. Technol. 211 (2016) 248-256.

[49] G.-B. Huang, Q.-Y. Zhu, C.-K. Siew, Extreme learning machine: theory and applications, Neurocomputing 70 (2006) 489-501.

[50] V. Kadirkamanathan, S. Fabri, Stable nonlinear adaptive control with growing radial basis function networks, IFAC Proc. Vol. 28 (1995) 245-250.

[51] Y. Lu, N. Sundararajan, P. Saratchandran, Performance evaluation of a sequential minimal radial basis function (RBF) neural network learning algorithm, IEEE Trans. Neural Netw. 9 (1998) 308-318.

[52] X. Wang, M. Han, Improved extreme learning machine for multivariate time series online sequential prediction, Eng. Appl. Artif. Intell. 40 (2015) 28-36.

[53] N.B. Ishola, O.O. Adeyemi, A.J. Adesina, V.O. Odude, O.O. Oyetunde A.A. Okeleye, A.R. Soji-Adekunle, E. Betiku, Adaptive neuro-fuzzy inference system-genetic algorithm vs, response surface methodology: a case of optimization of ferric sulfate-catalyzed esterification of palm kernel oil, Process Saf. Environ. Prot. 111 (2017) 211-220.

54] J. Milano, H.C. Ong, H.H. Masjuki, A.S. Silitonga, F. Kusumo, S. Dharma, A.H. Sebayang, M.Y. Cheah, C.-T. Wang, Physicochemical property enhancement of biodiesel synthesis from hybrid feedstocks of waste cooking vegetable oil and Beauty leaf oil through optimized alkaline-catalysed transesterification, Waste Manag. 80 (2018) 435-449.

[55] G. Knothe, L.F. Razon, Biodiesel fuels, Prog. Energy Combust. Sci. 58 (2017) 36-59.

[56] G. Knothe, Chapter 2 - biodiesel and its properties A2 - McKeon, thomas A, in: D.G. Hayes, D.F. Hildebrand, R.J. Weselake (Eds.), Industrial Oil Crops, AOCS Press, 2016, pp. 15-42.

[57] P. Tamilselvan, N. Nallusamy, S. Rajkumar, A comprehensive review on performance, combustion and emission characteristics of biodiesel fuelled diesel engines, Renew. Sustain. Energy Rev. 79 (2017) 1134-1159.

[58] J. Pullen, K. Saeed, An overview of biodiesel oxidation stability, Renew. Sus tain. Energy Rev. 16 (2012) 5924-5950.

[59] D.-S. Kim, H.-S. Kim, K.-T. Lee, D.-L. Hong, S.-R. Cho, J.H. Pan, Y.B. Park, Y.B. Lee, J.K. Kim, E.-C. Shin, Chemical characterization and oxidative stability of medium- and long-chain fatty acid profiles in tree-borne seed oils, J. Anal Methods Chem. 2018 (2018) 9 (2018) 2178684-2178684.

[60] N. Kumar, Oxidative stability of biodiesel: causes, effects and prevention, Fuel 190 (2017) 328-350. 
[61] S.K. Hoekman, A. Broch, C. Robbins, E. Ceniceros, M. Natarajan, Review of biodiesel composition, properties, and specifications, Renew. Sustain. Energy Rev. 16 (2012) 143-169.

[62] E.C. Zuleta, L. Baena, L.A. Rios, J.A. Calderón, The oxidative stability of biodiese and its impact on the deterioration of metallic and polymeric materials: review, J. Braz. Chem. Soc. 23 (2012) 2159-2175.

[63] I.A. Musa, The effects of alcohol to oil molar ratios and the type of alcohol on biodiesel production using transesterification process, Egypt. J. Petrol. 25 (2016) 21-31.

[64] L.M.d.S. Freire, I.M.G.d. Santos, J.R. de Carvalho Filho, A.M.T.d.M. Cordeiro, L.E.B. Soledade, V.J. Fernandes, A.S. de Araujo, A.G. de Souza, Influence of the synthesis process on the properties of flow and oxidative stability of biodiesel from Jatropha curcas biodiesel, Fuel 94 (2012) 313-316.

[65] I.M. Monirul, H.H. Masjuki, M.A. Kalam, N.W.M. Zulkifli, H.K. Rashedul, M.M. Rashed, H.K. Imdadul, M.H. Mosarof, A comprehensive review on biodiesel cold flow properties and oxidation stability along with their improvement processes, RSC Adv. 5 (2015) 86631-86655.

[66] F. Motasemi, F.N. Ani, A review on microwave-assisted production of biodiesel, Renew. Sustain. Energy Rev. 16 (2012) 4719-4733.

[67] K. Ponappa, V. Velmurugan, P.A. Franco, T.R. Kannan, R. Ragurajan, Optimization of biodiesel production from Ceiba Pentandra (kapok seed oil) using response surface methodology assisted by ultrasonic energy method, Int. J. Chemtech Res. 9 (2016) 794-803.

[68] A. Mazubert, M. Poux, J. Aubin, Intensified processes for FAME production from waste cooking oil: a technological review, Chem. Eng. J. 233 (2013) $201-223$.

[69] L. Buchori, I. Istadi, P. Purwanto, Advanced chemical reactor technologies for biodiesel production from vegetable oils - a review, Bull. Chem. React. Eng. Catal. 11 (2016) 406-430. 


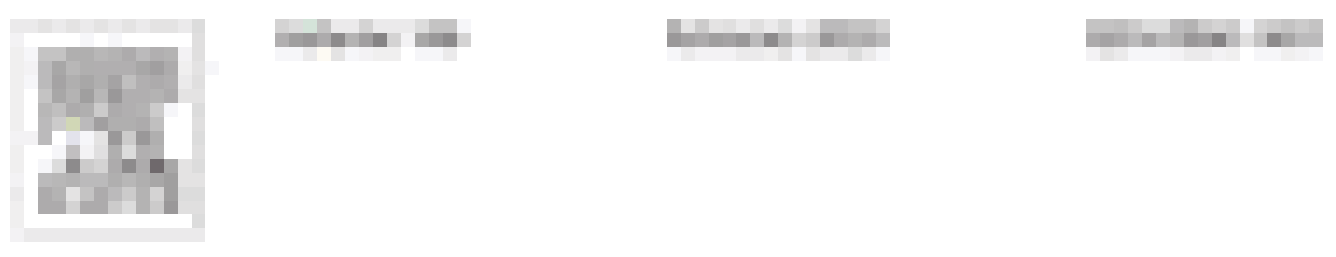

\section{Renewable Energy HH IMTRAHATHAL DHAhH}

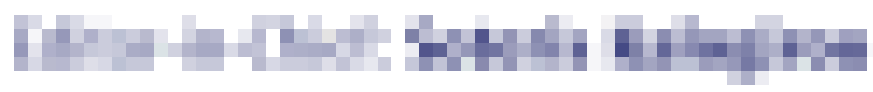

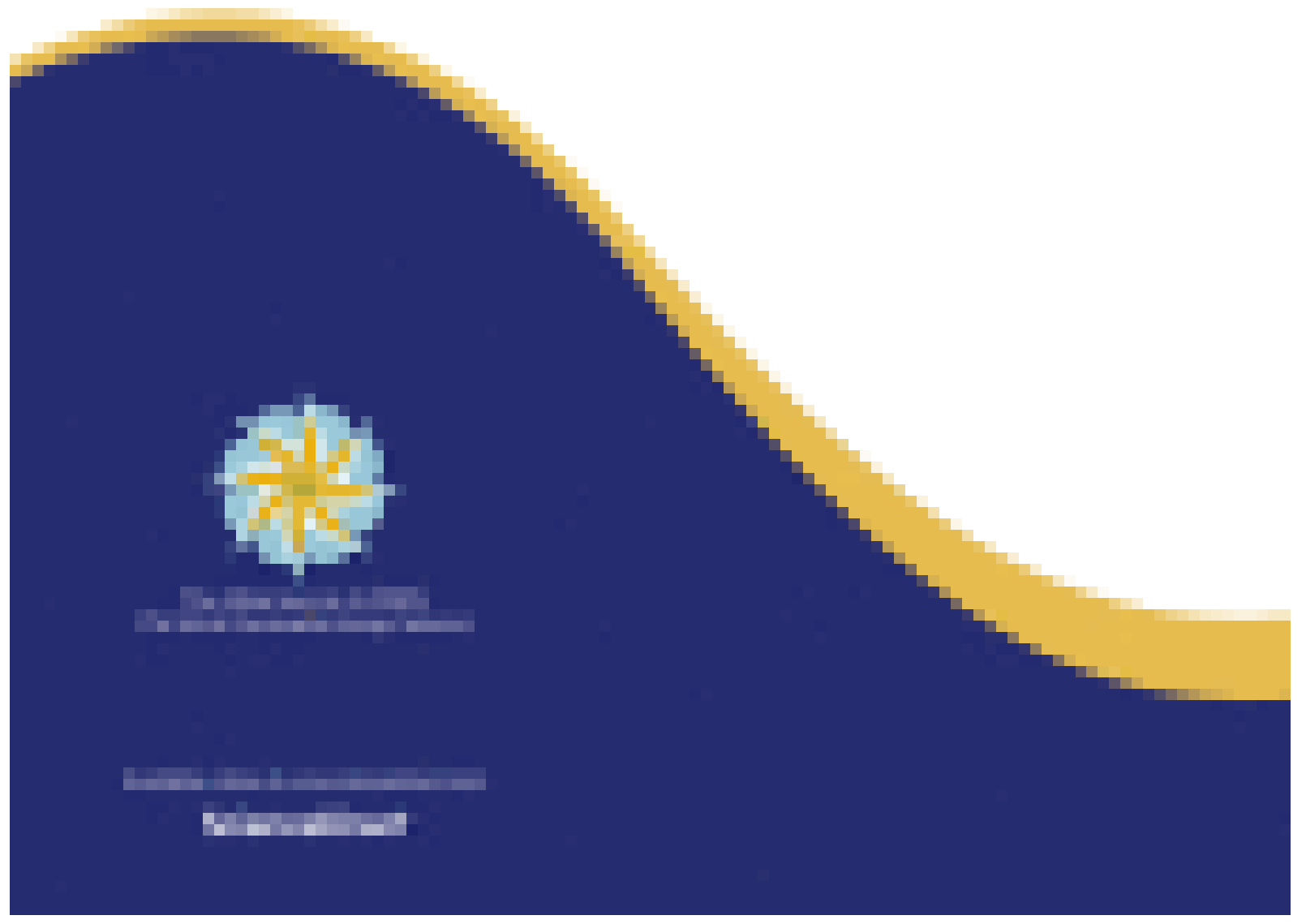




\section{ScienceDirect}

\section{Renewable Energy}

Supports open access

10.8

CiteScore

Guide for authors

Submit your article

8.001

Impact Factor

\section{三 Menu}

Q Search in this journal

\section{About the journal}

Incorporating Solar \& Wind Technology;

The journal, Renewable Energy, seeks to promote and disseminate knowledge on the various topics and technologies of renewable energy systems and components. The journal aims to serve researchers, engineers, economists, manufacturers, NGOs, associations and societies to help them keep abreast of ...

Read more

\section{1 weeks}

Publication Time

View all metrics 


\section{ScienceDirect}

\section{Renewable Energy}

Supports open access

10.8

CiteScore

Submit your article
8.001

Impact Factor

\section{About the journal}

Aims and scope Editorial board Abstracting and indexing

\section{Editor-in-Chief}

Soteris Kalogirou

Cyprus University of Technology, Lemesos, Cyprus

Email this editor $\lambda$

\section{Editorial Assistant}

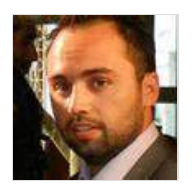

Gregoris Panayiotou

Cyprus University of Technology, Lemesos, Cyprus 


\section{Photovoltaics}

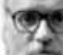

Viorel Badescu

Polytechnic University of Bucharest, Bucuresti, Romania

\section{Solid Biomass and Thermodynamics}

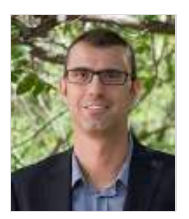

Sotirios Karellas

National Technical University Of Athens Laboratory of Steam Boilers and Thermal Plants, Zografou, Greece

Wind and PV Systems - Control and Grid Integration

\section{Ghanim Putrus}

Northumbria University, Newcastle Upon Tyne, United Kingdom

\section{Wind Systems}

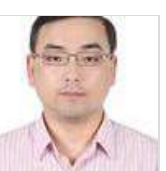

Mingming Zhang

Chinese Academy of Sciences, Beijing, China

\section{Solar Thermal Systems}

\section{Gilles Notton}

University of Corsica Pasquale Paoli, Corte, France 


\section{Subject Editors}

\section{Biomass}

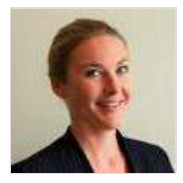

\section{Lise Appels}

KU Leuven, Leuven, Belgium

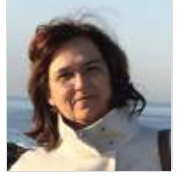

Nidia Caetano

Polytechnic Institute of Porto School of Engineering, Porto, Portugal

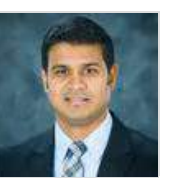

Veera Gnaneswar Gude

Mississippi State University, Mississippi State, Mississippi, United States of America

\section{Energy Storage and Geothermal}

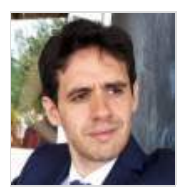

\section{Giorgio Besagni}

Polytechnic of Milan Department of Energy, Milano, Italy

\section{Maria Vahdati}

University of Reading, Reading, United Kingdom

\section{Hydrogen and Fuel Cells}

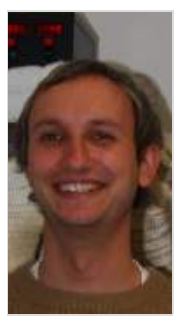

\section{Blaž Likozar}

National Institute of Chemistry, Department of Catalysis and Chemical Reaction Engineering, 
Ljubljana, Slovenia

\section{Hydropower}

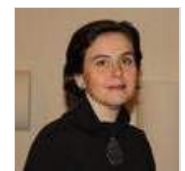

Petra Amparo López-Jiménez

Polytechnic University of Valencia, Valencia, Spain

\section{Low Energy Architecture and Buildings}

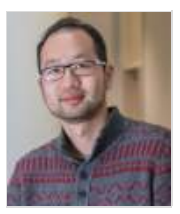

Yupeng (Jack) Wu

University of Nottingham Department of Architecture and Built Environment, Nottingham, United Kingdom

\section{Wind}

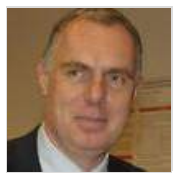

John K. Kaldellis

University of West Attica Soft Energy Applications and Environmental Protection Laboratory, Egaleo, Greece

\section{Ocean and Wind Energy}

\section{Arindam Banerjee}

Lehigh University Department of Mechanical Engineering and Mechanics, Bethlehem, Pennsylvania, United States of America

\section{Editorial Board Members}




\section{Biomass}

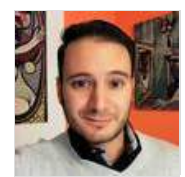

\section{Federico Battista}

University of Verona, Verona, Italy

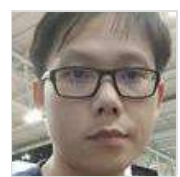

\section{Chin Kui Cheng}

University Malaysia Pahang Faculty of Chemical and Natural Resources Engineering, Kuantan, Malaysia

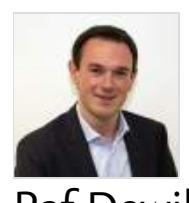

Raf Dewil

KU Leuven Science and Technology Group Department of Chemical Engineering, Heverlee, Belgium

\section{Ocean Energy}

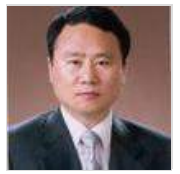

Young-Ho Lee

Korea Maritime and Ocean University, Busan, South Korea

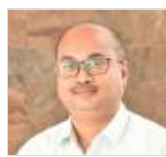

\section{Kaustubha Mohanty}

Indian Institute of Technology Guwahati, North Guwahati, India 


\section{Haijia Su}

Beijing University of Chemical Technology, Beijing, China

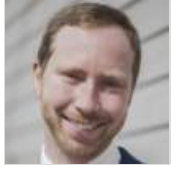

Christoph Wieland

Technical University of Munich, Munchen, Germany

\section{Shang-Shyng Yang}

China University of Science and Technology Department of Food Science, Taipei, Taiwan

\section{Control and Grid Integration}

\section{Desalination}

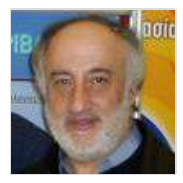

\section{Vassilios Belessiotis}

Nuclear Technology \& Radiation Protection, Athens, Greece

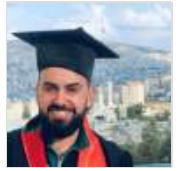

Tamer Khatib

An-Najah National University, Nablus, Palestine, State of

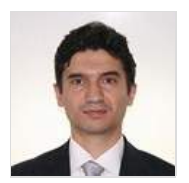

George Cristian Lazaroiu

Polytechnic University of Bucharest, Bucuresti, Romania

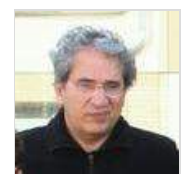

E. Mathioulakis

Nuclear Technology \& Radiation Protection, Athens, Greece

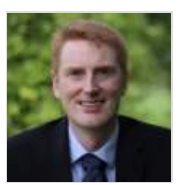




\section{Torsten Lund}

Vestas Wind Systems A/S, Aarhus, Denmark

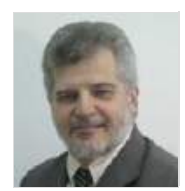

\section{Denizar Martins}

Federal University of Santa Catarina, Florianópolis, Brazil

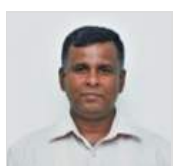

\section{Mahinsasa Narayana}

University of Moratuwa Department of Chemical and Process Engineering, Moratuwa, Sri Lanka

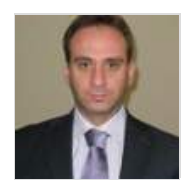

\section{Nick Papanikolaou}

Democritus University of Thrace Department of Electrical and Computer Engineeirng, Xanthi, Greece

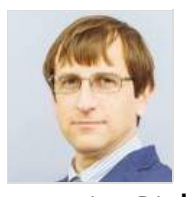

\section{Denis Sidorov}

FSBSI L A Melentiev Institute of Power Engineering Systems Siberian Branch of the Russian Academy of Sciences, Irkutsk, Russian Federation

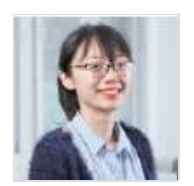

Yue Wang

University of Chichester, Chichester, United Kingdom

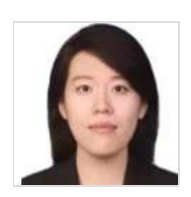

Jie Yan

North China Electric Power University, Beijing, China

\section{Energy and Buildings}




\section{Ricardo Fonseca Alves}

Federal Institute for Education Science and Technology of Goias, GOIANIA, Brazil

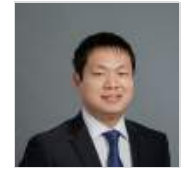

Long Shi

RMIT University, Melbourne, Victoria, Australia

\section{Energy Meteorology}

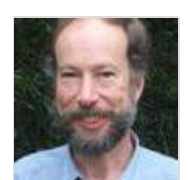

Ian Grant

Australian Bureau of Meteorology, Melbourne, Australia

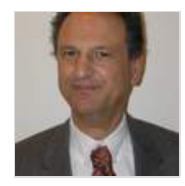

Harry Kambezidis

National Observatory of Athens, Athens, Greece

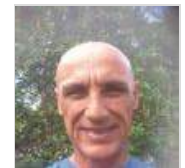

\section{Philippe Lauret}

Reunion University Laboratory for Physics and Engineering Mathematics for Energy and Environment and Construction, Saint-Denis, France

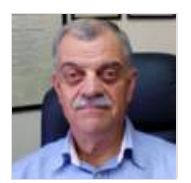

\section{Silas Michaelides}

The Cyprus Institute, Lefkosia, Cyprus

\section{Geothermal}

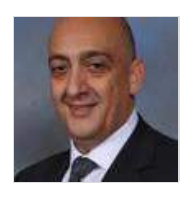




\section{Abdelmalek Bouazza}

Monash University, Clayton, Victoria, Australia

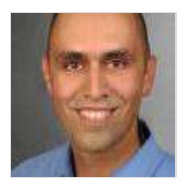

\section{Darius Mottaghy}

FH Aachen University of Applied Sciences Faculty of Energy Technology, Jülich, Germany

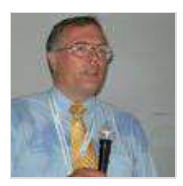

Ulrich Schmidtchen

German Hydrogen and Fuel Cell Association, Berlin, Germany

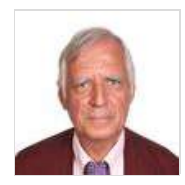

Umran Serpen

Istanbul Technical University, İstanbul, Turkey

\section{Hydrogen and Fuel Cells}

Low Energy Architecture and Building

Mahroo Eftekhari

Loughborough University, Loughborough, United Kingdom

\section{Ocean Energy Systems}

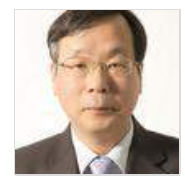

Kyoung Kwan Ahn

University of Ulsan, Ulsan, South Korea

\section{Photovoltaics}




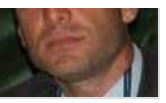

\section{Giorgio Graditi}

ENEA National Agency for New Technologies Energy and Economic Sustainable Development, Roma, Italy

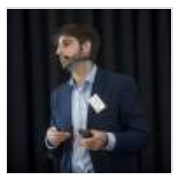

\section{Benedetto Nastasi}

University of Rome La Sapienza Department of Planning Design and Architectural Technology, Roma, Italy

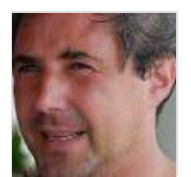

\section{Manuel Correia Guedes}

University of Lisbon Higher Technical Institute, Lisboa, Portugal

\section{Reza Hamidi}

Arkansas Technical University, Russellville, Arkansas, United States of America

\section{Rolf Hanitsch}

Technical University of Berlin, Berlin, Germany

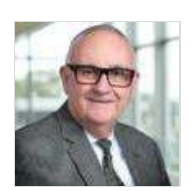

Derek Northwood

University of Windsor, Windsor, Canada

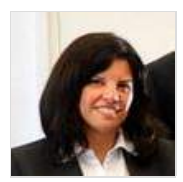

Neveen Hamza

Newcastle University, Newcastle Upon Tyne, United Kingdom 
University of Agder, Kristiansand, Norway

\section{Eftichios Koutroulis}

Technical University of Crete, Chania, Greece

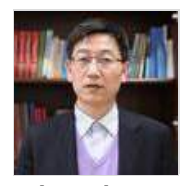

Shudong Wang

SPIC, Beijing, China

\section{Dionysia Kolokotsa}

Technical University of Crete, Chania, Greece

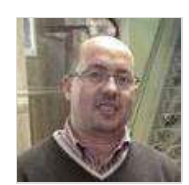

Adel Mellit

Jijel University, Jijel, Algeria

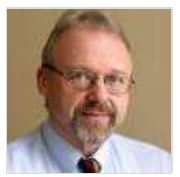

\section{Torgeir Moan}

Norwegian University of Science and Technology, Trondheim, Norway

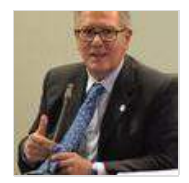

Francesco Morabito

University of Reggio Calabria Civil Energy Environmental and Materials Engineering, Reggio Calabria, Italy

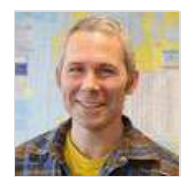

\section{Simon P. Neill}

Bangor University School of Ocean Sciences, Menai Bridge, United Kingdom 


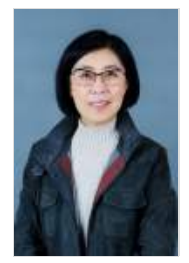

Runming Yao

University of Reading, Reading, UK; Chongqing University, Chongqing, China

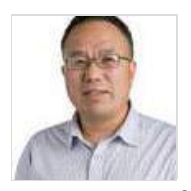

Wanan Sheng

SW Mare Marine Technology and Consultation, Cork, Ireland

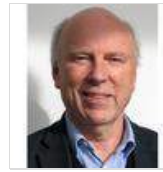

Peter Kenneth Stansby

The University of Manchester, Manchester, United Kingdom

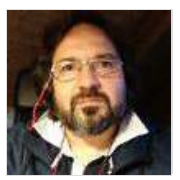

\section{Diego Vicinanza}

University of Campania Luigi Vanvitelli Department of Civil Engineering Construction and Environment, Aversa, Italy

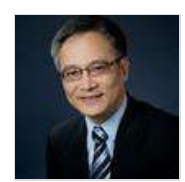

\section{Zhaoqing Yang}

Pacific Northwest National Laboratory Marine Sciences Laboratory, Sequim, Washington, United States of America

\section{Thermal Technology}

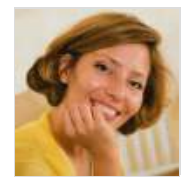

Annamaria Buonomano

University of Naples Federico II, Via Cintia, Naples, Italy 
Christian Cristofari

Environmental Sciences, Corte, France

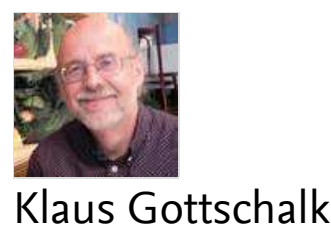

Leibniz Institute for Agricultural Engineering and Bioeconomy, Potsdam, Germany

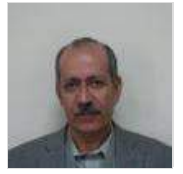

\section{Afif Hasan}

Birzeit University, Birzeit, Palestine, State of

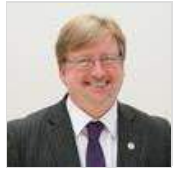

Brian Norton

Technological University Dublin, Dublin, Ireland

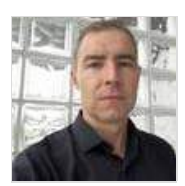

\section{Mervyn Smyth}

University of Ulster School of the Built Environment, Newtownabbey, United Kingdom

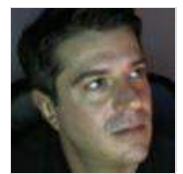

\section{Manolis Souliotis}

Panepistemio Dytikes Makedonias, Kozani, Greece

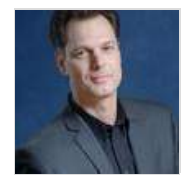

\section{Aggelos Zacharopoulos}

Ulster University, Coleraine, United Kingdom

\section{Policy}




\section{Rainer Hinrichs-Rahlwes}

German Renewable Energy Federation, Berlin, Germany

\section{Emilia Kondili}

University of West Attica, Aegaleo, Greece

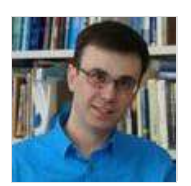

Lado Kurdgelashvili

University of Delaware, Newark, Delaware, United States of America

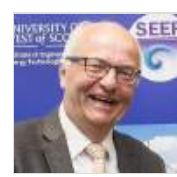

Henrik Lund

Aalborg University, Aalborg, Denmark

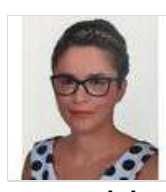

Angeliki Menegaki

Greek Agriculture Social Security, Komotini, Greece; Hellenic Open University, Patras, Greece

\section{Renewables in buildings}

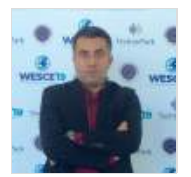

Alibakhsh Kasaeian

University of Tehran, Tehran, Iran

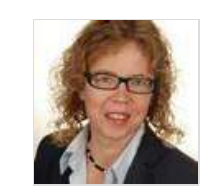

Ursula Eicker

HFT Stuttgart University of Applied Sciences, Stuttgart, Germany 


\section{Yanping Yuan}

Southwest Jiaotong University, Chengdu, China

\section{Wind Energy}

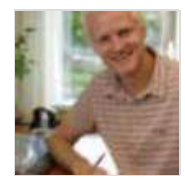

Morten Blarke

Aalborg University, Aalborg, Denmark

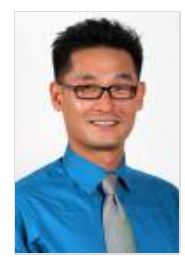

\section{Byungik Chang}

University of New Haven, West Haven, Connecticut, United States of America

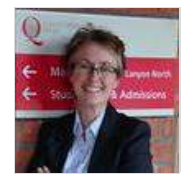

\section{Aoife Foley}

Queen's University Belfast, Belfast, United Kingdom

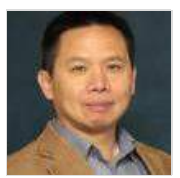

\section{David (Zhiwei) Gao}

Northumbria University Faculty of Engineering and Environment, Newcastle Upon Tyne, United Kingdom

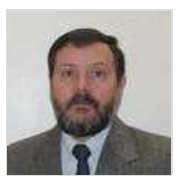

\section{Carlos Labriola}

National University of the Comahue, Neuquen, Argentina 


\section{Hua Ouyang}

Shanghai Jiao Tong University, Shanghai, China

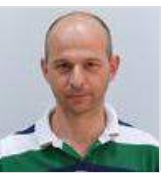

\section{Athanasios Sfetsos}

Nuclear Technology \& Radiation Protection, Athens, Greece

\section{Solar Thermal Systems}

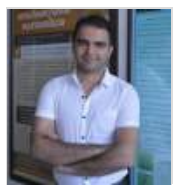

Omid Mahian

Xi'an Jiaotong University, Xi'an, China

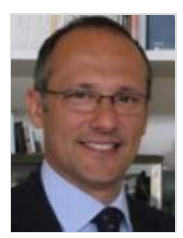

\section{Adolfo Palombo}

University of Naples Federico II, Via Cintia, Naples, Italy

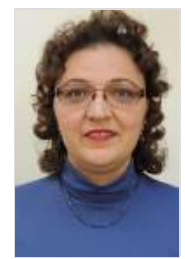

Camelia STANCIU

Polytechnic University of Bucharest, Bucuresti, Romania

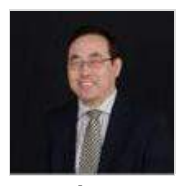

Xudong Zhao

University of Hull, Hull, United Kingdom

\section{Founding Editor}




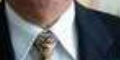

A.A.M. Sayigh

World Renewable Energy Congress Network, Brighton, United Kingdom

All members of the Editorial Board have identified their affiliated institutions or organizations, along with the corresponding country or geographic region. Elsevier remains neutral with regard to any jurisdictional claims.

ISSN: 0960-1481

Copyright (C) 2022 Elsevier Ltd. All rights reserved 


\section{ScienceDirect}

\section{Renewable Energy}

Supports open access

10.8

CiteScore

Guide for authors

Submit your article

\section{Volume 146}

Pages 1-2840 (February 2020)

Receive an update when the latest issues in this journal are published Sign in to set up alerts

\section{Research Papers}

Research article $\bigcirc$ Abstract only

Biodiesel synthesis from Ceiba pentandra oil by microwave irradiation-assisted transesterification: ELM modeling and optimization

A.S. Silitonga, A.H. Shamsuddin, T.M.I. Mahlia, Jassinne Milano, ... Hwai Chyuan Ong Pages 1278-1291

$\Perp$ Purchase PDF Article preview $\vee$ 
Research article $\bigcirc$ Abstract only

Multiscale prediction of localized hot-spot phenomena in solar cells

Ao Wang, Yimin Xuan

Pages 1292-1300

$\Downarrow$ Purchase PDF Article preview

Research article $\bigcirc$ Abstract only

Storage requirements for high grid penetration of wind and solar power for the MISO region of North America: A case study

Hannah Johlas, Shelby Witherby, James R. Doyle

Pages 1315-1324

$\downarrow$ Purchase PDF Article preview

Research article $\bigcirc$ Abstract only

Direct characterisation of the annual performance of solar thermal and heat pump systems using a six-day whole system test

Diego Menegon, Tomas Persson, Robert Haberl, Chris Bales, Michel Haller

Pages 1337-1353

$\Perp$ Purchase PDF Article preview

Research article $\bigcirc$ Abstract only

Assessment of a flexible solar hybrid thermal and electrical prototype

Brice Lecœuvre, Ghjuvan Antone Faggianelli, Jean-Louis Canaletti, Christian Cristofari

Pages 1354-1363

$\Perp$ Purchase PDF Article preview $\vee$

Research article $\bigcirc$ Abstract only

Pretreatment of quinoa straw with 1-butyl-3-methylimidazolium chloride and physiochemical characterization of biomass

Wei Xie, Yanjing Ren, Fan Jiang, Jibao Liang, Shuang-kui Du

Pages 1364-1371

$\Perp$ Purchase PDF Article preview $\vee$

Research article $\bigcirc$ Abstract only

Comparison between MRM simulations, CAMS and PVGIS databases FEEDBCK 
solar radiation components at the Methoni station, Greece

B.E. Psiloglou, H.D. Kambezidis, D.G. Kaskaoutis, D. Karagiannis, J.M. Polo

Pages 1372-1391

$\downarrow$ Purchase PDF Article preview $\vee$

Research article $\bigcirc$ Abstract only

Towards the development of biofuel production from paper mill effluent

Elhamossadat Vaez, Hamid Zilouei

Pages 1408-1415

$\Perp$ Purchase PDF Article preview $\vee$

Research article $\bigcirc$ Abstract only

An experimental work on the performance of new integration of photovoltaic panel with solar still in semi-arid climate conditions

Ayman Refat Abd Elbar, Hamdy Hassan

Pages 1429-1443

$\Perp$ Purchase PDF Article preview $\vee$

Research article $\bigcirc$ Abstract only

Economic assessment of flexible power generation from biogas plants in Germany's future electricity system

Markus Lauer, Uwe Leprich, Daniela Thrän

Pages 1471-1485

$\Perp$ Purchase PDF Article preview $\vee$

Research article $\bigcirc$ Abstract only

Simplified model to correct thermopile pyranometer solar radiation measurements for photovoltaic module yield estimation

I. Lillo-Bravo, M. Larrañeta, E. Núñez-Ortega, R. González-Galván

Pages 1486-1497

$\Perp$ Purchase PDF Article preview $\vee$

Research article $\bigcirc$ Abstract only

3D characterization of thermo-hydro-geological fields and estimation of power potential from Puga geothermal reservoir, Ladakh, India 
Shibani K. Jha, Harish Puppala, M.S. Mohan Kumar

Pages 1510-1523

$\Perp$ Purchase PDF Article preview $\vee$

Research article $\bigcirc$ Abstract only

Design optimization of a curved wind turbine blade using neural networks and an aero-elastic vortex method under turbulent inflow

Matias Sessarego, Ju Feng, Néstor Ramos-García, Sergio González Horcas

Pages 1524-1535

$\downarrow$ Purchase PDF Article preview $\vee$

Research article $\bigcirc$ Abstract only

Performance analysis of Aquifer Thermal Energy Storage (ATES)

Paul Fleuchaus, Simon Schüppler, Bas Godschalk, Guido Bakema, Philipp Blum

Pages 1536-1548

$\Perp$ Purchase PDF Article preview $\vee$

Research article $\bigcirc$ Abstract only

Maximizing energy production from hydropower dams using short-term weather forecasts

Shahryar Khalique Ahmad, Faisal Hossain

Pages 1560-1577

$\Perp$ Purchase PDF Article preview $\vee$

Research article $\bigcirc$ Abstract only

Experimental investigation on the thermal management performance of heat sink using low melting point alloy as phase change material

Liang Zhao, Yuming Xing, Xin Liu

Pages 1578-1587

$\Perp$ Purchase PDF Article preview $\vee$

Research article $\bigcirc$ Abstract only

Effect of pre-fermentation types on the potential of methane production and energy recovery from food waste

Kai Feng, Huan Li, Zhou Deng, Qiao Wang, ... Chengzhi Zheng 
Pages 1588-1595

$\downarrow$ Purchase PDF Article preview $\vee$

Research article $\bigcirc$ Abstract only

An efficiency-aware continuous adaptive proportional-integral velocity-feedback control for wave energy converters

Hoai-Nam Nguyen, Paolino Tona

Pages 1596-1608

$\Perp$ Purchase PDF Article preview $\vee$

Research article $\bigcirc$ Abstract only

Single cell oil and ethanol production by the oleaginous yeast Trichosporon fermentans utilizing dried sweet sorghum stalks lo Antonopoulou, Athanasios Spanopoulos, Leonidas Matsakas

Pages 1609-1617

$\downarrow$ Purchase PDF Article preview $\vee$

Research article $\bigcirc$ Abstract only

Solar water heating technical-economic potential in the household sector in Brazil Talita Cruz, Roberto Schaeffer, André F.P. Lucena, Sérgio Melo, Ricardo Dutra

Pages 1618-1639

$\Perp$ Purchase PDF Article preview $\vee$

Research article $\bigcirc$ Abstract only

Energetic valorization of the residual biomass produced during Jatropha curcas oil extraction

Mario A. Heredia Salgado, Luís A.C. Tarelho, Daniel Rivadeneira, Valeria Ramírez, Danny Sinche Pages 1640-1648

$\Perp$ Purchase PDF Article preview $\vee$

Research article $\bigcirc$ Abstract only

Suitability of hydrothermal carbonization to convert water hyacinth to added-value products

S. Román, B. Ledesma, A. Álvarez, C. Coronella, S.V. Qaramaleki

Pages 1649-1658 
Research article $\bigcirc$ Abstract only

Intensity dependent features of the light-induced gasification of the waste-derived coal-water compositions

Roman I. Egorov, Alexander S. Zaitsev, Hong Li, Xin Gao, Pavel A. Strizhak

Pages 1667-1675

$\Downarrow$ Purchase PDF Article preview

Research article $\bigcirc$ Abstract only

Numerical simulation and application of noise for high-power wind turbines with double blades based on large eddy simulation model

Jian Li, Ranhui Liu, Peng Yuan, Yanli Pei, ... Gang Wang

Pages 1682-1690

$\Downarrow$ Purchase PDF Article preview

Research article $\bigcirc$ Abstract only

Effects of carbonization conditions on the yield and fixed carbon content of biochar from pruned apple tree branches

Xuanmin Yang, Kang Kang, Ling Qiu, Lixin Zhao, Renhua Sun

Pages 1691-1699

$\Perp$ Purchase PDF Article preview

Research article $\bigcirc$ Abstract only

Activated carbons synthesized from unaltered and pelletized biomass wastes for biotar adsorption in different phases

Yafei Shen, Yuewei Zhou, Yuhong Fu, Niyu Zhang

Pages 1700-1709

$\Perp$ Purchase PDF Article preview

Research article $\bigcirc$ Abstract only

Slow pyrolysis of Defatted Seeds Cakes of African star apple and silk cotton for production of bio-oil

Muhammad Abdullahi Sokoto, Bijoy Biswas, Jitendra Kumar, Thallada Bhaskar

Pages 1710-1716 
$\Downarrow$ Purchase PDF Article preview

Research article $\bigcirc$ Abstract only

Mechanical strength of bio-coke from briquettes

L. Florentino-Madiedo, E. Díaz-Faes, C. Barriocanal

Pages 1717-1724

$\downarrow$ Purchase PDF Article preview $\vee$

Research article Open access

Sea trial results of a predictive algorithm at the Mutriku Wave power plant and controllers assessment based on a detailed plant model

François-Xavier Faÿ, Eider Robles, Marga Marcos, Endika Aldaiturriaga, Eduardo F. Camacho Pages 1725-1745

$\Downarrow$ Download PDF Article preview $\vee$

Research article $\bigcirc$ Abstract only

Robust estimation and diagnosis of wind turbine pitch misalignments at a wind farm level

Ester Sales-Setién, Ignacio Peñarrocha-Alós

Pages 1746-1765

$\downarrow$ Purchase PDF Article preview $\vee$

Research article $\bigcirc$ Abstract only

CFD model-based analysis and experimental assessment of key design parameters for an integrated unglazed metallic thermal collector façade

P. Elguezabal, A. Lopez, J.M. Blanco, J.A. Chica

Pages 1766-1780

$\Perp$ Purchase PDF Article preview $\vee$

Research article $\bigcirc$ Abstract only

A study on performance, emission and combustion characteristics of diesel engine powered by nano-emulsion of waste orange peel oil biodiesel

AR. Mahesh Kumar, M. Kannan, G. Nataraj

Pages 1781-1795

$\downarrow$ Purchase PDF Article preview $\vee$ 
Research article $\bigcirc$ Abstract only

Conversion of bio-oil extracted from Chlorella vulgaris micro algae to biodiesel via modified superparamagnetic nano-biocatalyst

Tahereh Nematian, Zeinab Salehi, Alireza Shakeri

Pages 1796-1804

$\Perp$ Purchase PDF Article preview

Research article $\bigcirc$ Abstract only

Dynamic modeling and free vibration analysis of horizontal axis wind turbine blades in the flap-wise direction

H. Jokar, M. Mahzoon, R. Vatankhah

Pages 1818-1832

$\Perp$ Purchase PDF Article preview

Research article $\bigcirc$ Abstract only

A novel approach based on hybrid vortex search algorithm and differential evolution for identifying the optimal parameters of PEM fuel cell Ahmed Fathy, Mohamed Abd Elaziz, Abdullah G. Alharbi

Pages 1833-1845

$\Perp$ Purchase PDF Article preview

Research article $\bigcirc$ Abstract only

Numerical simulation and experimental study of transient characteristics in an axial flow pump during start-up

Shifeng Fu, Yuan Zheng, Kan Kan, Huixiang Chen, ... Xiaoqing Tian

Pages 1879-1887

$\Perp$ Purchase PDF Article preview

Research article $\bigcirc$ Abstract only

Comparison and analysis on air-to-air and air-to-water heat pump heating systems Biao Xiao, Lin He, Shihang Zhang, Tingting Kong, ... R.Z. Wang

Pages 1888-1896

$\Perp$ Purchase PDF Article preview 
Performance comparison of medium temperature domestic packed bed latent heat storage systems

Ashmore Mawire, Tlotlo M. Lefenya, Chidiebere S. Ekwomadu, Katlego A. Lentswe, Adedamola B. Shobo

Pages 1897-1906

$\Perp$ Purchase PDF Article preview $\vee$

Research article $\bigcirc$ Abstract only

Using $\mathrm{CaCl}_{2} \cdot 6 \mathrm{H}_{2} \mathrm{O}$ as a phase change material for thermo-regulation and enhancing photovoltaic panels' conversion efficiency: Experimental study and TRNSYS validation

Mohammad Rezvanpour, Danial Borooghani, Farschad Torabi, Maryam Pazoki

Pages 1907-1921

$\Downarrow$ Purchase PDF Article preview $\vee$

Research article $\bigcirc$ Abstract only

Dynamic characteristics of load rejection process in a reversible pump-turbine Quan-Zhong Liu, Wen-Tao Su, Xiao-Bin Li, Ya-Ning Zhang

Pages 1922-1931

$\Perp$ Purchase PDF Article preview $\vee$

Research article Open access

The energy efficient use of an air handling unit for balancing an aquifer thermal energy storage system

Basar Bozkaya, Wim Zeiler

Pages 1932-1942

$\Perp$ Download PDF Article preview $\vee$

Research article $\bigcirc$ Abstract only

Design, development and performance investigation of solar Parabolic Trough Collector for large-scale solar power plants

K.S. Reddy, C. Ananthsornaraj

Pages 1943-1957

$\Perp$ Purchase PDF Article preview $\vee$ 
Research article $\bigcirc$ Abstract only

A parametric study and optimization of the fully-passive flapping-foil turbine at high Reynolds number

Matthieu Boudreau, Maxime Picard-Deland, Guy Dumas

Pages 1958-1975

\section{ע Purchase PDF Article preview}

Research article $\bigcirc$ Abstract only

The enhanced activity of base metal modified MgAl mixed oxides from sol-gel

hydrotalcite for ethylic transesterification

Renata A.B. Lima-Corrêa, Cínthia S. Castro, Amanda S. Damasceno, José M. Assaf

Pages 1984-1990

\section{$\downarrow$ Purchase PDF Article preview $\vee$}

Research article $\bigcirc$ Abstract only

Hydrodeoxygenation of phenols, acids, and ketones as model bio-oil for hydrocarbon fuel over Ni-based catalysts modified by Al, La and Ga

Zhiyu Li, Enchen Jiang, Xiwei Xu, Yan Sun, Ren Tu

Pages 1991-2007

\section{$\Perp$ Purchase PDF Article preview $\vee$}

Research article $\bigcirc$ Abstract only

Improving the thermal performance of ground air heat exchanger system using sandbentonite (in dry and wet condition) as backfilling material

Kamal Kumar Agrawal, Rohit Misra, Ghanshyam Das Agrawal

Pages 2008-2023

\section{$\Perp$ Purchase PDF Article preview $\vee$}

Research article $\bigcirc$ Abstract only

A numerical tool for modelling oscillating wave surge converter with nonlinear mechanical constraints

M. Brito, R.B. Canelas, O. García-Feal, J.M. Domínguez, ... L. Teixeira

Pages 2024-2043

$\Perp$ Purchase PDF Article preview $\vee$ 
Research article $\bigcirc$ Abstract only

Estimation of global solar radiation for the tropical wet climatic region of India: A theory of experimentation approach

Rahul G. Makade, Siddharth Chakrabarti, Basharat Jamil, C.N. Sakhale

Pages 2044-2059

\section{$\Perp$ Purchase PDF Article preview $\vee$}

Research article $\bigcirc$ Abstract only

To study the effect of different parameters on the thermal performance of ground-air heat exchanger system: In situ measurement

Kamal Kumar Agrawal, Rohit Misra, Ghanshyam Das Agrawal

Pages 2070-2083

\section{$\downarrow$ Purchase PDF Article preview $\vee$}

Research article $\bigcirc$ Abstract only

Energetic use of biogas from the anaerobic digestion of coffee wastewater in southern Minas Gerais, Brazil

Bruno Vasconcelos da Rosa Pin, Regina Mambeli Barros, Electo Eduardo Silva Lora, Oscar Almazan del Olmo, ... João Victor de Freitas Rocha

Pages 2084-2094

$\Downarrow$ Purchase PDF Article preview

Research article $\bigcirc$ Abstract only

Daily condition monitoring of grid-connected wind turbine via high-fidelity power curve and its comprehensive rating Yang Hu, Yunhua Xi, Chenyang Pan, Gengda Li, Baowei Chen

Pages 2095-2111

$\Perp$ Purchase PDF Article preview $\vee$

Research article $\bigcirc$ Abstract only

Gaussian Process Regression for numerical wind speed prediction enhancement Haoshu Cai, Xiaodong Jia, Jianshe Feng, Wenzhe Li, ... Jay Lee

Pages 2112-2123

$\Perp$ Purchase PDF Article preview $\vee$ 
Research article $\bigcirc$ Abstract only

Pyrolysis characteristics and products distribution of haematococcus pluvialis microalgae and its extraction residue

Zhiqiang Gong, Peiwen Fang, Zhenbo Wang, Xiaoyu Li, ... Fanzhi Meng

Pages 2134-2141

\section{$\Perp$ Purchase PDF Article preview}

Research article $\bigcirc$ Abstract only

The performance of a desiccant wheel air conditioning system with high-

temperature chilled water from natural cold source

Liu Chen, Yikun Tan

Pages 2142-2157

业 Purchase PDF Article preview

Research article $\bigcirc$ Abstract only

Effect of different co-solvents on biodiesel production from various low-cost feedstocks using $\mathrm{Sr}-\mathrm{Al}$ double oxides

Indu Ambat, Varsha Srivastava, Sidra Iftekhar, Esa Haapaniemi, Mika Sillanpää

Pages 2158-2169

$\Perp$ Purchase PDF Article preview $\vee$

Research article $\bigcirc$ Abstract only

An efficient rotational sampling method of wind fields for wind turbine blade fatigue analysis

Jianbing Chen, Yupeng Song, Yongbo Peng, Søren R.K. Nielsen, Zili Zhang

Pages 2170-2187

Purchase PDF Article preview

Research article $\bigcirc$ Abstract only

An explicit method to extract fitting parameters in lumped-parameter equivalent circuit model of industrial solar cells

Fei Yu, Gongyi Huang, Chuanzhong Xu

Pages 2188-2198

$\Perp$ Purchase PDF Article preview 
Research article $\bigcirc$ Abstract only

Exergo-environmental analysis of an indirect forced convection solar dryer for drying bitter gourd slices

S. Vijayan, T.V. Arjunan, Anil Kumar

Pages 2210-2223

\section{$\Perp$ Purchase PDF Article preview}

Research article $\bigcirc$ Abstract only

Study of quinoa plant residues as a way to produce energy through

thermogravimetric analysis and indexes estimation

Sergio Paniagua Bermejo, Alba Prado-Guerra, Ana Isabel García Pérez, Luis Fernando Calvo Prieto Pages 2224-2233

\section{$\Perp$ Purchase PDF Article preview}

Research article $\bigcirc$ Abstract only

Thermal performance enhancement of micro-grooved aluminum flat plate heat pipes applied in solar collectors

Gong Chen, Yong Tang, Longhua Duan, Heng Tang, ... Ting Fu

Pages 2234-2242

\section{$\downarrow$ Purchase PDF Article preview $\vee$}

Research article $\bigcirc$ Abstract only

Techno-economic analysis of using three Fresnel solar fields coupled to a thermal power plant for different cost of natural gas

Sadegh Khajepour, Mehran Ameri

Pages 2243-2254

\section{$\Perp$ Purchase PDF Article preview $\vee$}

Research article $\bigcirc$ Abstract only

Banana peduncle - A green and renewable heterogeneous base catalyst for biodiesel production from Ceiba pentandra oil Muthusamy Balajii, Subramaniapillai Niju

Pages 2255-2269

$\Perp$ Purchase PDF Article preview 
Research article $\bigcirc$ Abstract only

$\mathrm{N}$-doped hard carbon nanotubes derived from conjugated microporous polymer for electrocatalytic oxygen reduction reaction

Wanli Zhang, Hanxue Sun, Zhaoqi Zhu, Rui Jiao, ... An Li

Pages 2270-2280

$\Perp$ Purchase PDF Article preview $\vee$

Research article $\bigcirc$ Abstract only

Boron-Doped Carbon nanoparticles supported palladium as an efficient hydrogen evolution electrode in PEM water electrolysis

S. Shiva Kumar, V. Himabindu

Pages 2281-2290

$\Perp$ Purchase PDF Article preview $\vee$

Research article $\bigcirc$ Abstract only

Improved ADM1 for modelling C, N, P fates in anaerobic digestion process of pig manure and optimization approaches to biogas production

Heng Li, Zheng Chen, Dun Fu, Yuanpeng Wang, ... Qingbiao Li

Pages 2330-2336

$\Perp$ Purchase PDF Article preview $\vee$

Research article $\bigcirc$ Abstract only

Seasonal and interannual variability of the wave climate at a wave energy hotspot off the southwestern coast of Australia

Michael V.W. Cuttler, Jeff E. Hansen, Ryan J. Lowe

Pages 2337-2350

$\Perp$ Purchase PDF Article preview $\vee$

Research article $\bigcirc$ Abstract only

Experimental and optical performances of a solar CPV device using a linear Fresnel reflector concentrator

Gang Wang, Fasi Wang, Fan Shen, Tieliu Jiang, ... Peng Hu

Pages 2351-2361

$\Perp$ Purchase PDF Article preview $\vee$ 
Research article $\bigcirc$ Abstract only

Development of an eco-friendly deinking process for the production of bioethanol using diverse hazardous paper wastes

Sonu Saini, Preeti Chutani, Prabhat Kumar, Krishna Kant Sharma

Pages 2362-2373

\section{$\Downarrow$ Purchase PDF Article preview $\vee$}

Research article $\bigcirc$ Abstract only

Experimental modeling and optimization of biodiesel production from waste cooking oil and ethanol using $N, N^{\prime}, N^{\prime \prime}$-tris(3-dimethylaminopropyl)-guanidine as catalyst

Marko Racar, Fabio Faraguna, Zoran Glasovac, Ante Jukić

Pages 2374-2379

$\Perp$ Purchase PDF Article preview $\vee$

Research article $\bigcirc$ Abstract only

Improved high solid anaerobic digestion of chicken manure by moderate in situ ammonia stripping and its relation to metabolic pathway Shaojie Bi, Wei Qiao, Linpeng Xiong, Ahmed Mahdy, ... Renjie Dong

Pages 2380-2389

$\Perp$ Purchase PDF Article preview $\vee$

Research article $\bigcirc$ Abstract only

Wind actions on large-aperture parabolic trough solar collectors: Wind tunnel tests and structural analysis

Ulf Winkelmann, Christoph Kämper, Rüdiger Höffer, Patrick Forman, ... Peter Mark

Pages 2390-2407

$\Perp$ Purchase PDF Article preview $\vee$

Research article $\bigcirc$ Abstract only

Biohydrogen production using xylose or xylooligosaccharides derived from sugarcane bagasse obtained by hydrothermal and acid pretreatments Lívian Ribeiro Vasconcelos de Sá, Mariana de Oliveira Faber, Ayla Sant'Ana da Silva, Magali Christe Cammarota, Viridiana Santana Ferreira-Leitão

Pages 2408-2415 
$\Perp$ Purchase PDF Article preview $\checkmark$

Research article $\bigcirc$ Abstract only

Organosulfonic acid functionalized montmorillonites as solid catalysts for (trans) esterification of free fatty acids and (waste) oils

Sónia M. Silva, Andreia F. Peixoto, Cristina Freire

Pages 2416-2429

$\Downarrow$ Purchase PDF Article preview

Research article $\bigcirc$ Abstract only

Developing of the new models in solar radiation estimation with curve fitting based on moving least-squares approximation

Ayse Gul Kaplan, Yusuf Alper Kaplan

Pages 2462-2471

$\Downarrow$ Purchase PDF Article preview

Research article $\bigcirc$ Abstract only

Validation of a CFD-based numerical wave tank model for the power production assessment of the wavestar ocean wave energy converter

Christian Windt, Josh Davidson, Edward J. Ransley, Deborah Greaves, ... John V. Ringwood

Pages 2499-2516

ע Purchase PDF Article preview

Research article $\bigcirc$ Abstract only

Hydrogen generation by aluminum alloy corrosion in aqueous acid solutions promoted by nanometal: Kinetics study

A.L. Martínez-Salazar, J.A. Melo-Banda, M.A. Coronel-García, J.J. González-Barbosa, J.M. DomínguezEsquivel

Pages 2517-2523

$\Perp$ Purchase PDF Article preview $\vee$

Research article $\bigcirc$ Abstract only

Refrigeration characteristics of a hybrid heat dissipation photovoltaic-thermal heat pump under various ambient conditions on summer night

Shixiang Lu, Jili Zhang, Ruobing Liang, Chao Zhou

Pages 2524-2534

FEEDBACK 口 
$\Perp$ Purchase PDF Article preview $\vee$

Research article $\bigcirc$ Abstract only

Analysis of hazards related to syngas production and transport

Katarzyna Stolecka, Andrzej Rusin

Pages 2535-2555

$\downarrow$ Purchase PDF Article preview $\vee$

Research article $\bigcirc$ Abstract only

Experimental investigations on the thermal stability of $\mathrm{Na}_{2} \mathrm{CO}_{3}-\mathrm{K}_{2} \mathrm{CO}_{3}$ eutectic salt/ceramic composites for high temperature energy storage

Bao-rang Li, Hui Tan, Yu Liu, Qi Liu, ... Xiao-ze Du

Pages 2556-2565

$\Downarrow$ Purchase PDF Article preview $\vee$

Research article $\bigcirc$ Abstract only

Optimal process design for integrated municipal waste management with energy recovery in Argentina

Betzabet Morero, Agustín F. Montagna, Enrique A. Campanella, Diego C. Cafaro

Pages 2626-2636

$\downarrow$ Purchase PDF Article preview $\vee$

Research article $\bigcirc$ Abstract only

Experimental study on thermal conductivity of paraffin-based shape-stabilized phase change material with hybrid carbon nano-additives

Y. Qu, S. Wang, D. Zhou, Y. Tian

Pages 2637-2645

$\Perp$ Purchase PDF Article preview $\vee$

Research article $\bigcirc$ Abstract only

Effect of intermittent operation on the thermal efficiency of energy tunnels under varying tunnel air temperature

Oluwaseun Ogunleye, Rao Martand Singh, Francesco Cecinato, Jung Chan Choi

Pages 2646-2658

$\downarrow$ Purchase PDF Article preview $\vee$ 
Research article $\bigcirc$ Abstract only

A mobile energy harvesting autowinder - Build and test

Abby George, David Moline, John Wagner

Pages 2659-2667

$\Downarrow$ Purchase PDF Article preview

Research article $\bigcirc$ Abstract only

The effect of pollutants on leakage current and power degradation of photovoltaic modules

Ping Wang, Meiya Kong, Wei Du, Linhong Wang, Lei Ni

Pages 2668-2675

ע Purchase PDF Article preview

Research article $\bigcirc$ Abstract only

Box-Behnken optimization of glycerol transesterification reaction to glycerol

carbonate over calcined oil palm fuel ash derived catalyst

Patrick U. Okoye, Song Wang, Waheed Ahmad Khanday, Sanxi Li, ... Linnan Zhang

Pages 2676-2687

$\Perp$ Purchase PDF Article preview

Research article $\bigcirc$ Abstract only

The optimal design and operation strategy of renewable energy-CCHP coupled system applied in five building objects

Xingyi Zhu, Xiangyan Zhan, Hao Liang, Xuyue Zheng, ... Yingru Zhao

Pages 2700-2715

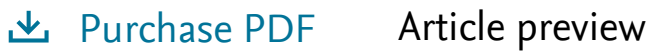

Research article $\bigcirc$ Abstract only

Hot dry rock (HDR) hydraulic fracturing propagation and impact factors assessment via sensitivity indicator

Weiwu Ma, Yadan Wang, Xiaotian Wu, Gang Liu

Pages 2716-2723

$\downarrow$ Purchase PDF Article preview 
Application of iron oxide $\left(\mathrm{Fe}_{3} \mathrm{O}_{4}\right)$ nanoparticles during the two-stage anaerobic digestion with waste sludge: Impact on the biogas production and the substrate metabolism

Zengshuai Zhang, Liang Guo, Yi Wang, Yangguo Zhao, ... Yiding Guo

Pages 2724-2735

$\Downarrow$ Purchase PDF Article preview $\vee$

Research article $\bigcirc$ Abstract only

A Markovian approach to power generation capacity assessment of floating wave energy converters

Ehsan Arzaghi, Mohammad Mahdi Abaei, Rouzbeh Abbassi, Malgorzata O'Reilly, ... Irene Penesis Pages 2736-2743

$\Downarrow$ Purchase PDF Article preview $\vee$

Research article $\bigcirc$ Abstract only

Analysis and optimization of a methanol reactor with the adsorption of carbon monoxide and water

Grazia Leonzio

Pages 2744-2757

$\Perp$ Purchase PDF Article preview

Research article $\bigcirc$ Abstract only

Enhanced anaerobic fermentation of dairy manure by microelectrolysis in electric and magnetic fields

Guangfei Qu, Pei Lv, Yingying Cai, Can Tu, ... Ping Ning

Pages 2758-2765

$\Perp$ Purchase PDF Article preview

Research article Open access

Comparative assessment of control strategies for the biradial turbine in the Mutriku OWC plant

François-Xavier Fä̈, João C. Henriques, James Kelly, Markus Mueller, ... Marga Marcos

Pages 2766-2784

$\Perp$ Download PDF Article preview 
Research article $\bigcirc$ Abstract only

An applied methodology for optimal sizing and placement of hybrid power source in remote area of South Algeria

Brahim Berbaoui, Rachid Dehini, Mustapha Hatti

Pages 2785-2796

$\Perp$ Purchase PDF Article preview $\vee$

Research article $\bigcirc$ Abstract only

A new diffuse luminous efficacy model for daylight availability in Burgos, Spain

M.I. Dieste-Velasco, M. Díez-Mediavilla, C. Alonso-Tristán, D. González-Peña, ... T. García-Calderón

Pages 2812-2826

$\Perp$ Purchase PDF Article preview $\vee$

Research article $\bigcirc$ Abstract only

Onshore wind farm siting prioritization based on investment profitability for Greece Evelyn G. Sakka, Dimitrios V. Bilionis, Dimitrios Vamvatsikos, Charis J. Gantes

Pages 2827-2839

$\Perp$ Purchase PDF Article preview $\vee$

Special Section on Recent Advances in Photovoltaic Science and Technologies: A Special Issue of Papers Presented at the International Conference on Photovoltaic Technologies (PVCon2018, July 4-6, 2018, Ankara Turkey)

Research article $\bigcirc$ Abstract only

Solar cells fabricated by spray pyrolysis deposited $\mathrm{Cu}_{2} \mathrm{CdSnS}_{4}$ thin films

Ahmet Tombak, Tahsin Kilicoglu, Yusuf Selim Ocak

Pages 1465-1470

$\Perp$ Purchase PDF Article preview

Research article $\bigcirc$ Abstract only

The controllable deposition of large area roll-to-roll sputtered ito thin films for photovoltaic applications

Yasemin Demirhan, Hasan Koseoglu, Fulya Turkoglu, Zemzem Uyanik, ... Lutfi Ozyuzer

Pages 1549-1559 
Research article $\bigcirc$ Abstract only

Enhancing the efficiency of mixed halide mesoporous perovskite solar cells by introducing amine modified graphene oxide buffer layer

Çiğdem Şahin, Halide Diker, Dimitra Sygkridou, Canan Varlikli, Elias Stathatos

Pages 1659-1666

\section{$\Perp$ Purchase PDF Article preview}

Research article $\bigcirc$ Abstract only

Optimization of PERC fabrication based on loss analysis in an industrially relevant environment: First results from GÜNAM photovoltaic line (GPVL)

Fırat Es, Emel Semiz, Efe Orhan, Ezgi Genç, ... Raşit Turan

Pages 1676-1681

$\Perp$ Purchase PDF Article preview

Special issue on CFD simulation of biomass thermochemical conversion: model development, practical application and experimental validation

Research article $\bigcirc$ Abstract only

Natural-draft flow and heat transfer in a plancha-type biomass cookstove José Núñez, Miguel F. Moctezuma-Sánchez, Elizabeth M. Fisher, Víctor M. Berrueta, ... Alberto Beltrán

Pages 727-736

$\Perp$ Purchase PDF Article preview

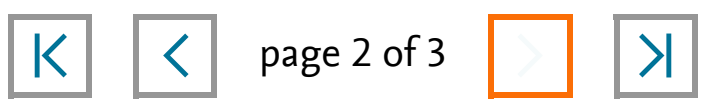




\section{Renewable Energy}

\section{COUNTRY}

United Kingdom

Universites and research tions in United Kingdom
SUBJECT AREA AND CATEGORY

Energy

Renewable Energy, Sustainability and

the Environment

ISSN

09601481
PUBUSHER

Elsevier BV

1991.2021
H-INDEX

\section{1}

Journals

TORMATION

Homepage

How to publish in this journa

Contact

SCOPE

The journal, Renewable Energy, seeks to promote and disseminate knowledge on the various topics and technologies of renewable energy systems and components. The journal aims to serve researchers, engineers, economists, manufacturers, NGOs, associations and societies to help them keep abreast of new developments in their specialist fields and to apply alternative energy solutions to current practices. Sustainable Energy Technologies and GBR International Journal of Green Energy

USA
$76 \%$

similarity
Sustainable Energy

$74 \%$
International Journal of

Energy and Environmenta

$74 \%$

similarity options :
Energy Reviews

$72 \%$ similarity 


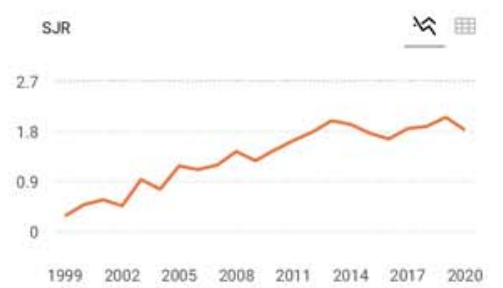

$\begin{array}{llllllllllll} & 2002 & 2005 & 2000 & 2011 & 2014 & 2017 & 2020\end{array}$

Total Cites Self-Cites

$40 \mathrm{k}$

$20 k$

$\begin{array}{llllllll}1999 & 2002 & 2005 & 2008 & 2011 & 2014 & 2017 & 2020\end{array}$

\$International Collaboration

合四

40

20

0

$\begin{array}{llllllll}1999 & 2002 & 2005 & 2008 & 2011 & 2014 & 2017 & 2020\end{array}$
Total Documents 施曲

4k

0

$\begin{array}{llllllll}1999 & 2002 & 2005 & 2008 & 2011 & 2014 & 2017 & 2020\end{array}$

External Cites per Doc Cites per Doc 证 团

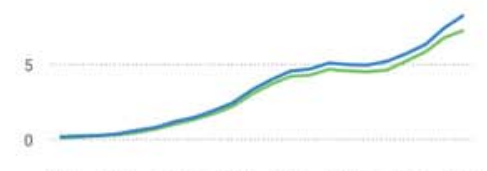

$\begin{array}{llllllll}1999 & 2002 & 2005 & 2008 & 2011 & 2014 & 2017 & 2020\end{array}$

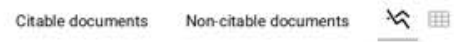

$2 n$

$\begin{array}{llllllll}1999 & 2002 & 2005 & 2008 & 2011 & 2014 & 2017 & 2020\end{array}$

\section{G SCImago Graphica}

Explore, visually

communicate and make

sense of data with our new

free tool.

Get it

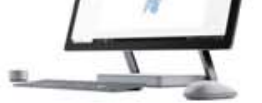

Citations per document

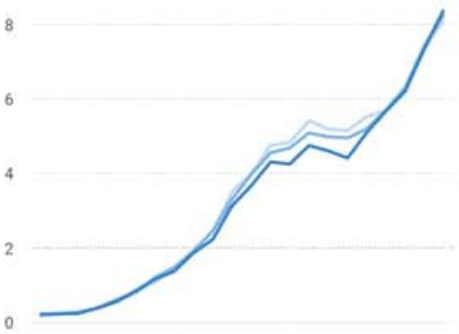

$\begin{array}{llllllll}1999 & 2002 & 2005 & 2008 & 2011 & 2014 & 2017 & 2020\end{array}$

Cites / Doc. (4 years)

- Cites / Doc, (2 years)

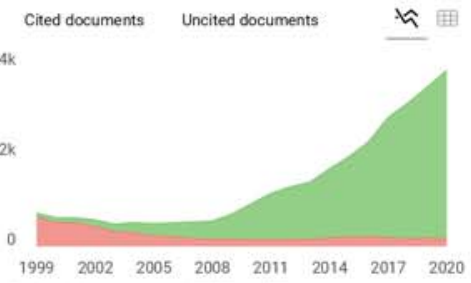

Metrics based on Scopus@ data as of April 2021

sara rhandouriate 7 months ago

Chère équipe des énergies renouvelables,

Pourriez-vous s'il vous plait mindiquer le temps de traitement moyen pour la publication d'un article dans votre journal, et aussi combien de temps pour l'examen et la détermination de

l'acceptation et du rejet d'un article à partir du moment où il est envoyé au journal $*$ ?, je voudrais savoir si je peux publier mon article de recherche sur cette revue gratuitement si non combien la pup darticle de 18 pages

reply

\section{Melanie Ortiz 6 months ago}

Dear Sara,

Thank you for contacting us.

We are sorry to tell you that SCImago Journal \& Country Rank is not a journal. SJR is a portal with scientometric indicators of journals indexed in Elsevier/Scopus.

Unfortunately, we cannot help you with your request, we suggest you visit the journal's

homepage or contact the journal's editorial staff , so they could inform you more deeply. Best Regards, SCImago Team

F Fabian Eze 2years ago

Hello,

Please I would like to know if I can publish my research article on this journal for free.

Thanks.

reply 
Dear Fabian, thank you very much for your comment, we suggest you look for authors

instructions/submission guidelines in the journal's website. Best Regards, SCImago Team

Masoud Mohammadhosein 2 years ago

A very good site. Thanks

reply

MARZIE 3 years ago

Hit This is Marzie, She is associated professor in Herat university in Afghanista. Could you please tell me how long time for review and determining accept and reject of any article from the time of sending it to journal?

thank you very much.

reply

Elena Corera 3 years ago

Dear Marzie,

thank you very much for your comment, unfortunately we cannot help you with your request. We suggest you check author's instructions in journal website. You can find that information in SJR website https://www.scimagoj.com

Best Regards,

SClmago Team

Dear Renewable Energy team,

Could you please let me know about the average processing time for publishing a paper in you journal. Plus my theses are already available online. The work that I am planning to submit Renewable Energy journal is based on my thesis and has almost $52 \%$ similarity index with my thesis. This work has not been published in any conference or journal anywhere else. Now, do I have to modify my thesis accordingly or will it work with a self-citation.

Tanvir

reply

6

Elena Corera 3 years ago

Dear Tanvir,

thank you very much for your comment, unfortunately we cannot help you with your request. We suggest you look for author's instructions in the journal's website.

Best Regards,

SCImago Team

Q Qahtan A Abed 3 years ago

thanks

reply

Email 
Im not a robot

Submit

The users of Scimago Journal \& Country Rank have the possibility to dialogue through comments linked to a

specific journal. The purpose is to have a forum in which general doubts about the processes of publication in the

journal, experiences and other issues derived from the publication of papers are resolved. For topics on particular

articles, maintain the dialogue through the usual channels with your editor.

coconut shell carbonization

pellet torrefaction

POWERMAX Is a Leading Supplier of Biomass Pyrolysis Systerns

powermaxgasifiers.cont

OPEN

coconut shell carbonization

pellet torrefaction

POWERMAX Is a Leading Supplier of Biomass Pyrolysis Systems

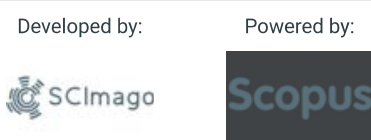

Follow us on @ScimagoJR

Scimago Lab, Copyright 2007-2020. Data Source: Scopus ${ }^{\circledR}$ 


\section{Source details}

\section{Renewable Energy}

Formerly known as: Solar and Wind Technology

Scopus coverage years: from 1991 to Present

Publisher: Elsevier

ISSN: 0960-1481

Subject area: Energy: Renewable Energy, Sustainability and the Environment

Source type: Journal
View all documents >
Set document alert
$\square$ Save to source list Source Homepage

10.8

SJR 2020

1.825

SNIP 2020

2.381 (i)

(i)

(i)

\section{CiteScore CiteScore rank \& trend Scopus content coverage}

i Improved CiteScore methodology

CiteScore 2020 counts the citations received in 2017-2020 to articles, reviews, conference papers, book chapters and data papers published in 2017-2020, and divides this by the number of publications published in 2017-2020. Learn more >

CiteScore 2020

$10.8=\frac{65,273 \text { Citations } 2017-2020}{6,029 \text { Documents } 2017-2020}$

Calculated on 05 May, 2021
CiteScoreTracker 2021 (i)

$$
12.9=\frac{88,273 \text { Citations to date }}{6,831 \text { Documents to date }}
$$

\section{CiteScore rank 2020 (i)}

\begin{tabular}{|c|c|c|}
\hline Category & Rank & Percentile \\
\hline Energy & & \\
\hline $\begin{array}{l}\text { Renewable Energy, } \\
\text { Sustainability and } \\
\text { the Environment }\end{array}$ & \#23/195 & 88th \\
\hline
\end{tabular}

View CiteScore methodology $>$ CiteScore FAQ $>$ Add CiteScore to your site $\mathbb{P}$ 


\section{About Scopus}

\section{What is Scopus}

Content coverage

Scopus blog

Scopus API

Privacy matters

\section{Language}

日本語に切り替える

切换到简体中文

切換到繁體中文

Русский язык

\section{Customer Service}

Help

Contact us

\section{ELSEVIER Terms and conditions $\pi$ Privacy policy $\pi$}

Copyright (C Elsevier B.V त. All rights reserved. Scopus ${ }^{\circledR}$ is a registered trademark of Elsevier B.V.

We use cookies to help provide and enhance our service and tailor content. By continuing, you agree to the use

QRELX

of cookies. 